\title{
SIMULAÇÃO DA DISTRIBUIÇÃO ESPACIAL DA ÁGUA EM SOLO IRRIGADO COM GOTEJADOR
}

\author{
TARLEI ARRIEL BOTREL
}

Orientador: Prof. Dr. ANTONIO FERNANDO L. OLITTA

Tese apresentada à Escola Superior de Agricultura "Luiz de Queiroz", da Universidade de São Paulo, para obtenção do título de Doutor em Agronomia. Área de concentração: Solos $\theta$ Nutrição de Plantas.

PIRACICABA

Estado de São Paulo - Brasil

Junho -1988 
Botrel, Tarlei Arriel

B749s Simulação da distribuição espacial da água em solo irrigado com gotejador. Piracicaba, 1988.

$61 p$.

Tese - ESALQ

Bibliografia.

\begin{abstract}
1. Agua do solo - Distribuição - Simulação 2. Irrigaça por gotejamento 3. Modelo matemático 4. Solo irrigado - Água Distribuiçāo I. Escola Superior de Agricul tura Luiz de Queiroz. Piracicaba
\end{abstract}

$\operatorname{CDD} 631.7$ 


\section{SIMULAÇÃO DA DISTRIBUIÇĀOO ESPACIAL DA ÁGUA EM SOLO IRRIGADO COM GOTEJADOR}

TARLEI ARRIEL BOTREL

Aprovada em: 08.07.1988

Comissão julgadora:

Prof. Dr. Antonio Fernando Lordelo Olitta

ESALQ/USP

Prof. Dr. Antonio Sanchez de Oliveira

ESALQ/USP

Prof. Dr. Paulo Leonel Libandi

ESALQ/USP

Prof. Dr. Dirceu Brasil Vieira

FEL/UNICAMP

Prof. Dr. José Renato Zanini

FEIS/UNESP

Prof. Dr. ANTONIO AERNANDO LORDELO OLITTA Orientador 


\section{AGRADECIMENTOS}

A Deus, fela fé e perseverança concedida em tadas as momentas.

Ao Prof. Antonio Fernando Lordelo olitta, pela orientaçăo, amizade e apoio recebidos no decorrer do curso e na realizaçăo deste trabalho.

A Escola Superior de Agricultura "Luiz de Queiroz" por intermedio do Departamento de Engenharia Fural, pela acolhida e apoio concedido.

Aos demais professores, funcionários e estagiários do Departamento de Engenharia Rural pelas sugestores, ajuda e convivio amigo.

Enfim, a todos que, direta ou indiretamente, contribuiram para o exito deste trabalho. 
SUMÁRIO

Fágina

1. INTRODUC̆Ä $\ldots \ldots \ldots \ldots \ldots \ldots \ldots \ldots \ldots \ldots \ldots \ldots \ldots \ldots$

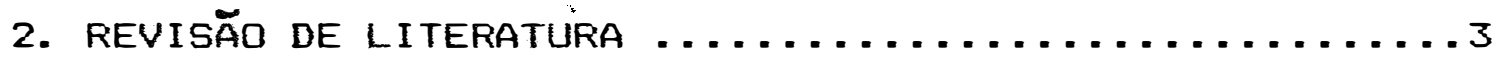

3. MATERIAL E MÉtODOS .............................

3.1. Localizą̧a ..........................

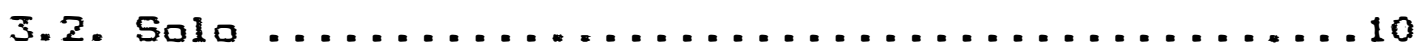

3.2.1. Classificaça e análise mecânica .......10

3.2.2. Determinaça das curvas caracteristicas..11

3.2.3. Determinaça da densidade aparente e da condutividade hidráulica saturada ......12

3.2.4. Análise mecánica ................13

3.3. Instal açăo do experimento no campo ..........14

3.3.1. Suprimento de água ............... 14

3.3 .2 Obtença da umidade do solo ..........14

3.4. Simuląaro dos dados $\ldots \ldots \ldots \ldots \ldots \ldots \ldots \ldots \ldots \ldots$

4. RESUltados E disCUSSÃo. . . . . . . . . . . . . 24

4.1. Curva de retençăo, condutividade hidráulica e ajuste das equacbes ...................24

4.2. Observaçbes de campo .................. 32

4.3. Dados simulados ....................40 


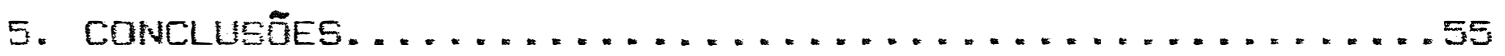

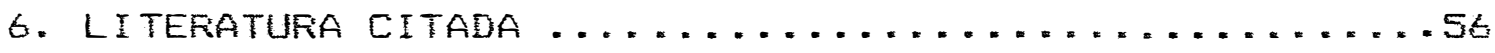




\section{LISTA DE FIGURAS}

FIGURA

PAGINA

1 - Esquema do mecanismo de suprimento d'água.

2 - Esquema dos anéis concenticos, utilizados no desenvolvimento do modelo para simula५⿱ă da distribuiçăo espacial da água no solo...........................

3 - Fluxograma utilizado no desenvolvimento do programa para simulaçă dos dados........

4 - Representaça grafica da curva de retença e dados experimentais, para a profundidade de 0 a $20 \mathrm{~cm} \ldots \ldots \ldots \ldots \ldots \ldots \ldots \ldots . . . \ldots$

5 - Representaça gráfica da curva de retença e dados experimentais, para a profundidade

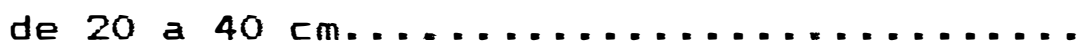


6 - Representaça gráfica da curva de retençăo e dados experimentais, para a profundidade

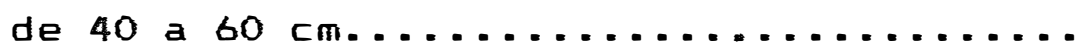

7 - Representaçăo gráfica da curva de retençăo e dados experimentais, para a profundidade

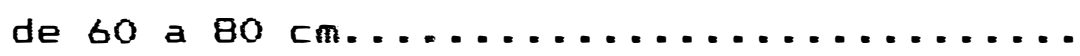

8 - Representaçăo gráfica da curva de retençăo e dados experimentais, para a profundidade

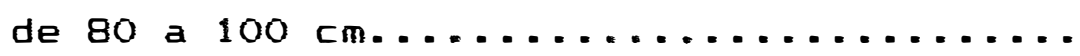

9 - Ferfil de distribuiçăo de umidade observado no solo, 24 horas após o inicio da aplicaçăo de água.....................41

10 - Ferfil de distribuiça de umidade observado no solo, 48 horas após o inicio da aplicaçăo de água....................... 42

11 - Ferfil de distribuiça de umidade observado no solo, 72 horas após o inicio da aplicaçă de agua.............................. 
FIGURA

PÁGINA

12 - Ferfil de distribuiço de umidade, simulado para 24 horas, após o inicio da aplica-

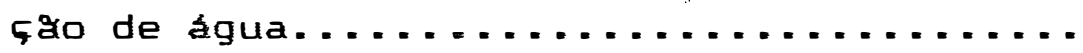

13 - Ferfil de distribuiça de umidade, simulado para 48 horas, após o inicio da aplica૬ăo de água.......................

14 - Ferfil de distribuiça de umidade, simulado para 72 horas, após o inicio da aplica-

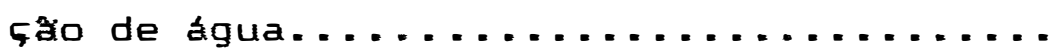




\section{LISTA DE TABELAS}

TABELA

FÁGINA

1 - Análise mecanica e classe textural do perfil do solo latossol vermelho amare-

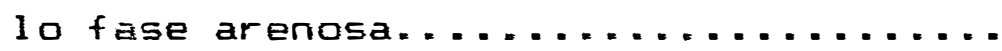

2 - Tensao versus umidade volumetrica para as diferentes profundidades.....

3 - Farametros de ajustes das curvas de retenção da água no solo a equaçăo (B)...

4 - Condutividade hidráulica saturada, densidade global e unidade inicial das diferentes camadas..................

5 - Umidade volumetrica (\%) observada para - perfil de distribuiçăo de água no soIo sob fonte puntiforme, com vazåo de $101 / \mathrm{h}, 24$ horas após o inicio da apli-

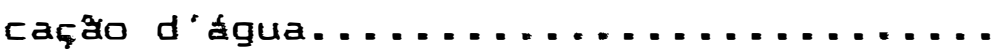


b - Umidade volumétrica (\%) observada para o perfil de distribuigaro de água no solo sob fonte puntiforme, com vazao de $101 / h, 48$ horas após o inicio da apli-

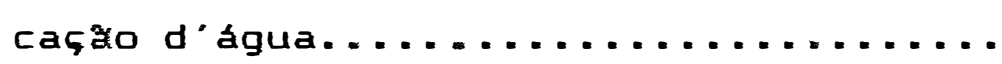

7 - Umidade volumétrica (\%) observada para - perfil de distribuiça de água no 50lo sob fonte puntiforme, com vazao de $101 / h, 72$ horas após o inicio da aplicaçăo d’água......................

8 - Umidade volumetrica média $(\%)$ observada para o perfil de distribuiça de água no solo sob fonte puntiforme, com vazaro de $10 \mathrm{l} / \mathrm{h}, 24$ horas apos 0 inicio da aplicaçào d’água.................

9 - Umidade volumétrica média $(\%)$ observada para o perfil de distribuiça de água no solo sob fonte puntiforme, com vazao de $10 \mathrm{l} / \mathrm{h}, 48$ horas apds 0 inicio da aplicaçăo d’água................. 
10 - Umidade volumétrica média (\%) observada para o perfil de distribuigăo de água no solo sob fonte puntiforme, com vazao de $101 / \mathrm{h}, 72$ horas apus o inicio da aplicặăo d’água.................

11 - Unidade volumétrica (\%) estimada para - perfil molhado pela fonte puntiforme, sob vazao de $101 / h, 24$ horas apos o inicio da aplicaçăo d’água............

12 - Umidade volumetrica $(\%)$ estimada para - perfil molhado pela fonte puntiforme, sob vazao de $101 / \mathrm{h}, 48$ horas apos 0 inicio da aplicaçăo d’água............

13 - Umidade volumetrica $(\%)$ estimada para - perfil molhado pela fonte puntiforme, sob vazao de $101 / \mathrm{h}, 72$ horas apos o inicio da aplicạ̧ăo d’água...........

14 - Unidade volumétrica média (\%) estimada para o perfil molhado pela fonte puntiforme, 24 horas apos o inicio da apli-

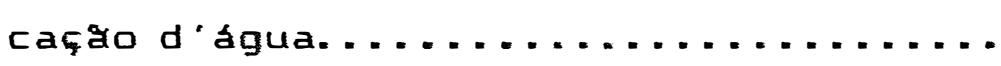


15 - Umidade volumétrica média (\%) estimada para o perfil molhado pela fonte puntiforme, 48 horas após o inicio da apli-

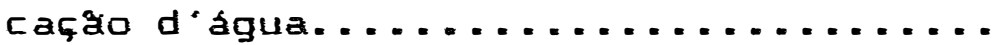

16 - Umidade volumétrica média $(\%)$ estimada para o perfil molhado pela fonte puntiforme, 72 horas após o inicio da apli-

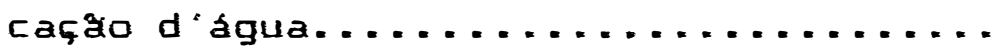


SIMULACão DA Distribuiç̃ó ESPACIAL DA ÁGUA EM SOLO IRRIGADO COM GOTEJADOR

Autor: TARLEI ARRIEL BOTREL Orientador: FROF. DR. ANTONIO FERNANDO LORDELO OLITTA

RESUMO

Este trabalio teve como objetivo apresentar e testar sob condiçoes de campo, um modelo matemático para computador, onde se permite estimar a distribuiça espacial da água em solos sob fontes puntiformes. 0 modelo utilizou a equaça de Darcy para fluxo d’água em solos nào saturados, e o principio de conservaço das massas. A condutividade hidráulica em funça da umidade para utilizacăo na equaçăo de Darcy, foi determinada a partir da curva de retença de umidade e da condutividade hidráulica saturada, seguindo metodologia descrita por VAN GENUCHTEN (1980). Os parametros necessários a simulaçăo foram: umidade inicial, curva caracteristica de retençăo de água do solo, condutividade 
hidráulica saturada, densidade global, vazăo da fonte puntiforme e volume d'água aplicado. 0 modelo foi testado en condiçes de campo num latossol vermelho amarelo fase arenosa submetido a uma fonte puntiforme com vazao de 10 ith e un volume total de 30 litros. 0 perfil de distribuicăo de umidade, foi avaliado por metodo gravimetrico, sendo as amostras obtidas utilizando-se de um trado amostrador. As amostras foram colihidas nos tempos de 24,48 e 72 horas, após o inicio da aplicạ̧o d’água. Ds perfis de distribuiça de água no solo observados, apresentaram-se semelhante aos simulados pelo modelo. 
SIMULATION OF WATER SPACIAL DISTRIBUITION IN IRRIGATED SOILS UNDER TRICKLE SOURCES

Author: TARLEI ARRIEL BOTREL Adviser: PROF: DR. ANTONIO FERNANDO LORDELO OLITTA

SUMHARY

The objective of this work was to test, under field conditions, a mathematical model for computer to estimate the spatial distribution of water in soils under point sources. The model uses Darcy's equation and the principle of mass conservation. The hydraulic conductivity as a function of soil-water content to be utilized in Darcy's equation was determined from soil water retention curve and saturated hydraulic conductivity according to VAN GENUCHTEN (1980) method. The parameters used for the simulation were: initial soil-water content, soil-water retention curve, saturated hydraulic conductivity, soil bulk density, flow of the point source and volume of applied water. The model was tested under field conditions in a Red Yellow Latosol (textural class: sand clay) under 
a point source with a flow of $101 / \mathrm{h}$ and a total volume of 3* 1. The soil water distribution profile was evaluated by gravimetric method being the samples taken from the field with a sampling auger. Samples were taken 24,48 and 72 hours after beginning of water application. Observed data and those determined by simulation profiles were similar, showning the potenciality of the model for future works. 
1 - INTRODUCÃAO

Nas culturas irrigadas, o conhecimento da capacidade do solo em armazenar água é de fundamental importancia no estabelecimento da frequencia da irrigaça.

Nos métodos em que a irrigaça é feita de modo a molhar toda a superficie do terreno, esta capacidade de armazenamento de água pelo solo é facilmente estimada por testes de laboratório ou de campo, onde se determina a capacidade de campo e o ponto de murchamento permanente. Porém, existem técnicas de irrigaçăo em que apenas parte do solo funciona como armazém de água para as plantas, e nesse caso para se estimar a capacidade do solo em armazenar água, torna-se necessário conhecer a distribuiço espacial desta água no solo, quando irrigado. Um dos métodos que molha apenas parte do solo e que vem sendo bastante utilizado é a irrigaço por gotejamento. Nesse método de irrigaçăo, a água é lançada por fontes puntiformes sob a copa da planta diretamente sobre a regiăo do sistema radicular. Para projetar com critério um sistema de irrigacaro por gotejamento, necessita-se conhecer a distribuiço espacial da água no 
solo, o que possibilita verificar a regiao com umidade adequada para desenvolvimento das raízes.

A fim de dar subsidios à elaboraça de projetos de irrigaça por gotejamento, este trabalho tem por objetivo apresentar e testar em condiços de campo, um modelo matemático para computador, onde se permite estimar a distribuigăo espacial da água no solo, proveniente de fontes puntiformes, como é o caso dos gotejadores. 


\section{2) - REVISÃO DE LITERATURA}

A já consagrada equaçăo desenvolvida por Darcy em 1856 para movimento de água em solos saturados, juntamente com os conceitos de potencial de água no solo definidos por Buckingham em 1907 foram utilizados para equacionar o movimento da água em solos nåo saturados. A equaçă de Euchingham-Darcy para movimento da água em solos nå saturados é a seguinte:

$$
\mathbf{q}=-K(h) \vec{\nabla} h
$$

sendo:

$$
\begin{aligned}
q= & \text { densidade de } f l u \times 0, L T^{-1} ; \\
K(h)= & \text { condutividade hidráulica em meio nao } \\
& \text { saturado, } L T_{-1} \\
+ & \text { gradiente do potencial hidráulico, } \\
& \text { admensional; }
\end{aligned}
$$

RICHARDS (1931) combinou a equaçăo de Buchingham-Darcy com a equaça da continuidade e obteve a equaço diferencial geral que descreve a movimento nå saturado da água em solos, a qual e conhecida na literatura de ciencia do solo como Equaça de Richards. 
Este autor, neste mesmo trabalio, foi o primeiro a apresentar um método de determinaça da condutividade hidráulica. Seu método consistiu em se utilizar uma pequena coluna de solo, entre duas placas porosas de ceramica, mantendo um gradiente de potencial constante entre as extremidades da coluna, por meio de colunas de água. Uma vez atingida a condiça de equilibrio dinámico, a condutividade hidráulica era facilmente estimada por meio da equaçăo de Buchingham - Darcy.

o valor da condutividade hidráulica $K(\theta)$ decresce muito rapidamente quando a umidade volumétrica ( $\theta$ ) afasta de seu valor de saturaça, o que segundo FHILIP (1969) se deve as seguintes raz8es: a) a seço transversal total disponivel ao fluxo decresce muito rapidamente com a diminuiço da umidade volumetrica; b) os poros maiores do solo săo esvaziados primeiramente com o decréscimo de $\theta$ e c) para casos de baixos valores de umidade, aumenta-se a probabilidade de a água ocorrer em poros separados rompendo a contato hidráulico no solo.

GARDNER

(1958) propos

uma relaça

exponencial entre a condutividade hidráulica e o potencial matricial, na forma:

$$
K(h)=K(O) e^{\alpha h}
$$

em que:

$$
K(h)=\text { condutividade hidráulica em meio năo }
$$




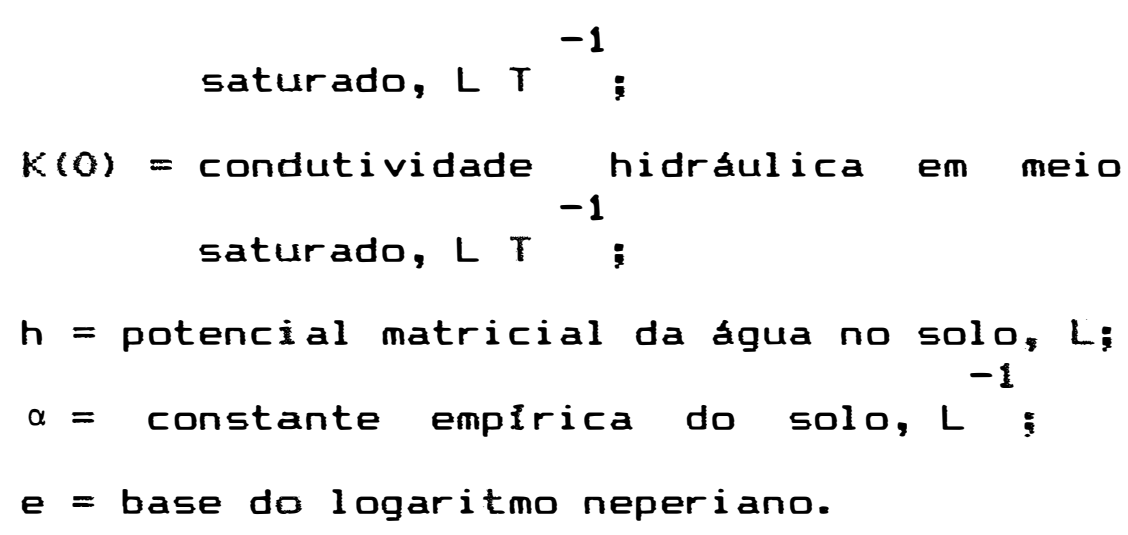

MUALEN (1976), VAN GENUCHEN (1980), e PAULETTO (1986) apresentaram o desenvolvimento de equaç8es que permitem estimar a condutividade hidráulica nå saturada a partir da curva de retençăo da água no solo e da condutividade hidráulica saturada. Os dados obtidos por estas equaçies foram comparados com os obtidos a campo, e todas chegaram a resultados satisfatórios, para as condiç8es as quais foram desenvolvidos os experimentos.

GARDNER $\mathrm{M}$ MAYHOGH (1958) estudaram o movimento da água em solo năo saturado bi e tri dimensionalmente. No caso bi dimensional horizontal, verificaram que o volume de água absorvido em funço do tempo, e uma funço linear que năo passa pela origem dos eixos. No caso tri dimensional, o volume de água infiltrado é uma funça linear do tempo elevado a potencia de $3 / 2$.

HILLEL (1970) estudando infiltraçăo em sulcos de irrigaça, verificou que a infiltraçăo se corre- 
laciona com o tempo, de acordo com a seguinte equặo:

$$
I=s t^{(1 / 2)}+a t
$$

onde (I) é a infiltraça acumulada durante o tempo ( $t$ ), (5) é un coeficiente do solo, que expressa o efeito do gradiente de suç̧̃o, e (a) um coeficiente que expressa o efeito da gravidade.

KELLER e KAFMELI (1974) salientam a importáncia da área molhada em relaça a área total, de uma cultura irrigada por gotejamento. Os autores apresentam um gráfico onde é mostrado a produçăo relativa, em funça da percentagem da área molhada pelos gotejadores, e uma tabela onde se pode estimar a percentagem da área molhada, em funça do tipo de solo e da vazăo do gotejador.

NIELSEN et alii (1962) estudaram o avanco horizontal da água em colunas de solo sob diferentes tensßes, e observaram que existe uma relacăo linear entre - caminhamento da água e a raiz quadrada do tempo.

ROTH (1974) conduziu um experimento onde foi aplicado água em tres diferentes taxas por uma fonte puntiforme, em solo arenoso, notando que a volume de solo molhado, teve maior influencia da quantidade de água aplicada que da taxa de aplicaçăo. Observou ainda, que o perfil molhado tinha forma aproximadamente circular para volumes de água inferiores a 95 litros, e forma eliptica para volumes maiores. 
Frocurando verificar o efeito da vazao de um gotejador no escoamento da água em amostras do horizonte Ap de um latossolo roxo, DELLA LIBERA (1976) ajustou equaços que representam o avanco da frente de molhamento en funça do tempo. O trabalho foi desenvolvido em condiçies de laboratório onde se utilizou vazbes eritre 1 e $81 / h$ sob declividades de 0 a $26,8 \%$

FALL et alii (1981) desenvolveram um modelo matemático, para estudo do movimento da água em macieiras irrigada por gotejamento, onde os testes de campo mostraram resultados próximos aos estimados pelo modelo. MOSTAGHIMI et alii (1981) conduziram un experimento em laboratório com um gotejador isolado submetido a diferentes taxas de aplicaça de água; este estudo mostrou que o incremento na taxa de aplicaça aumentou o alcance vertical e reduziu o alcance horizontal do perfil molhado pelo gotejador. 0 resultado foi contrário ao encontrado por BRANDT et alii (1971).

KHATRI et alii (1985) desenvalveram um programa de computador baseado no principio de conservaça das massas e na lei de Darcy, para estudar o movimento da água aplicada por um gotejador no solo, considerando tambem a extraçào da água pelas ralzes. Foi observado que distribuiça de água no solo é dependente do montante de água aplicado, das caracteristicas de retençăo de água do solo, da umidade inicial e da quantidade de água extraida 
pelas ralzes.

SHANI et alii (1985) afirmaram que a distribuifăo da água no perfil de solo é afetada pela taxa de descarga dos gotejadores, pelo intervalo de aplicaça de água, pelas propriedades hidráulicas do solo e pela distribuiço das raizes, sendo que estas em sistemas de irrigaçăo por gotejamento se apresentam adensadas e limitadas a uma profundidade de até 30 cm da camada superior do 5010.

CHANIM et alii (1985) partiram da equaço da infiltraçăo acumulada de Kostiakov e desenvolveram um modelo matematico simples, para estimar a infiltraça horizontal e vertical, bem como a volume de solo molhado por um gotejador, onde os dados necessários ao modelo foram as constantes a, b, e c da equaça de infiltraçăo de Kostiakov e a umidade inicial. Este modelo foi comparado com dados de campo e obtiveram-se resultados satisfatorios.

$$
\text { Vários autores como BRADT et alii (1971), }
$$

PHILIP (1971), WARRICK (1974), RAATS (1974), E WARRICK (1985) apresentaram modelos matemáticos que permitiram estimar o potencial da água ou umidade nas coordenadas $x$, $y, e z$ em funço do tempo, para fontes puntiformes. As limitaçbes destes modelos sao a aplicabilidade apenas em solos homogéneos, e a linearizaçăo da funçăo $k(\theta)$, sendo observado por WARRICK (1974) que a umidade em irrigaçies 
frequentes varia sobre uma escala limitada, o que torna a linearizaçăo da funçăo $K(\theta)$ mais aceitável.

MARTINEZ ( 1981 ) fez uma comparaça entre os potenciais da água no solo medidos no campo e simulados pelo modelo de WARRICK e LOMEN (1976). o trabalho foi desenvolvido em solo podźlico vermelho amarelo cambico submetido a vazaro de $62,5 \mathrm{~cm} 3 / \mathrm{h}$, sendo o potencial matricial medido através de tensiometros instalados em 20 pontos no perfil do solo. Foi observado que as diferencas entre potenciais medidos e estimados tenderam a aumentar com o tempo de aplicaçăo de água.

NAKAYAMA e BUCKS (1986) apresentaram um modelo simplificado para estimar o bulbo molhado por uma fonte puntiforme. Tal modelo baseou-se no principio da conservaço das massas, e assumiu o formato semiesférico para o bulbo. Foi observado que para tempos longos," a frente de molhamento tende a aprofundar e desviar mais da semi-esfera proposta pelo modelo. 
3 - MAterial e MÉtodos

3.1 - Localizaçăo

o experimento foi conduzido em uma área experimental, localizada dentro do campus da Escola Superior de Agricultura "Luiz de Queiroz", da Universidade de Săo Paulo, em Piracicaba, cujas coordenadas geográficas så: $20^{\circ} 42^{\circ} 30^{\circ}$ de latitude sul, e $47^{\circ} 38^{\circ} 00^{\circ}$ de longitude oeste, a 580 metros de altitude.

$3.2-5010$

3.2 .1 - Classificaçăo e análise mecânica

0 solo utilizado neste experimento foi um latossol vermelho amarelo fase arenosa, sendo classificado por RANZANI et alii(1966) como serie sertåozinho, com a seguinte descriça de horizontes:

Ap - 25 cm: pardo avermelhado claro (5 YR 6/4; 4/6 úmido): salpicado de areia lavada; barro arenoso macico; macio, muito friável, nåo 
Plastico, nato pegajoso; galerias, policas; raizes firias, comum; carvoes, comum; ph 4,3; Iimite suave, difuso.

Ci 25 - $75 \mathrm{~cm}$ : pardo avermelhado (5YF 6/4; 4/6 umido); barro arenoso grosso; macico; macio, muito friavel, nâo plastico, nâo pegajoso; galerias, pouco; raizes finas; comums carvoles, comum; ph 4,3 simite suave, di f̧uso.

\section{2 .2 - Determinaço das curvas caracteristicas}

Uma trincheire foi aberta ao lado da déa de testes, a fim de coletar amostras com extrutura indeformada, utilizando-se de aneis amostradores de $\exists \subset m$ de diametro por $3 \mathrm{~cm}$ de altura. As camadas amostradas para obtença em laboratorio das curvas caracteristicas, foram de, $0-20,20-40,40-60,60-80$, e $80-100$ cm, sendo 4 amostras para cada profundidade. Fara tensobe ate 203 cm de coluna d'água, foi utilizado mesa de tensào li kpe = $10,204 \mathrm{~cm}$ de coluna d'agual, e acima deste valor foi Utilizada camera de fichards com placas porosas de cer-竞再ica. 
3.2 .3 - Determinaçăo da densidade global e da condutividade hidráulica saturada.

Utilizando a mesma trincheira aberta para coletar as amostras para determinaça das curvas caracteristicas, foram coletadas também amostras utilizando cilindros amostradores de $7,5 \mathrm{~cm}$ de diametro por 7,5 cm de altura, para obtença da densidade global e da condutividade hidráulica saturada, sendo colhidas amostras as mesmas profundidades daquelas utilizadas para elaboraça das curvas caracteristicas.

A condutividade hidráulica saturada, foi determinada utilizando-se de um permeâmetro de carga constante, onde foi mantida uma carga hidráulica fixa de 2,3 cm por meio de um recipiente, cujo nivel foi mantido constante por um fluxo contínuo de água e o excesso drenado por transbordamento do recipiente. Após a saturaçăo da amostra, foi determinado o volume de água que atravessou a amostra no intervalo de tempo de uma hora e trinta minutos. Com a relaçăo entre o volume por unidade de tempo e a área da seç̧a transversal da amostra, obteve-se o fluxo, que juntamente com a diferenca de potencial hidráulico entre as extremidades da amostra, pode-se obter a condutividade hidráulica saturada, utilizando-se da equạ̧o de Darcy. 


\subsection{4 - Análise mecánica}

A análise mecánica deste solo, foi feita por LIBARDI (1978) mostrando os resultados apresentados na Tabela 1 .

Podemos observar que o solo apresenta-se bastante homogeneo, sendo classificado como areno-argiloso em todo perfil.

Tabela 1 - Análise mecanica e classe textural do perfil do solo latossol vermelho amarelo fase arenosa.

Profundidade \% Argila \% Silte \% Areia Classe textural (cm)

\begin{tabular}{rrrrl}
15 & 18,17 & 4,72 & 77,11 & areno-argiloso \\
30 & 27,88 & 14,22 & 67,90 & areno-argiloso \\
45 & 26,82 & 5,29 & 67,89 & areno-argiloso \\
60 & 27,10 & 3,93 & 68,97 & areno-argiloso \\
75 & 28,11 & 3,08 & 68,81 & areno-argiloso \\
90 & 27,87 & 3,16 & 68,97 & areno-argiloso \\
105 & 26,41 & 5,51 & 68,87 & areno-argiloso \\
120 & 28,31 & 3,61 & 68,08 & areno-argiloso \\
135 & 26,78 & 5,20 & 68,02 & areno-argiloso \\
\hline
\end{tabular}


3.3 - Instalaçăo do Experimento no campo

3.3.1 - Suprimento de água

Para simular o efeito de um gotejador, utilizou-se de um tubo capilar com dispositivo para dosar a quantidade de água ldosador de soro para utilizaçăo em hospitais). Este tubo capilar foi acoplado a um reservatório de nivel constante com capacidade de 8 litros de água, o qual era abastecido por outro reservatório metálico con capacidade de 70 litros. 0 nivel no reservatório de 8 litros era mantido constante pela utilizaçăo de uma bóia. A Figura 1 mostra esquematicamente - mecanismo de suprimento de água.

o dispositivo dosador foi ajustado para uma vazao de 10 litros por hora e o tempo de funcionamento de 3 horas, a que levou a un consumo de 30 litros de água.

\subsection{2 - Obtença da umidade do solo}

A fim de comparar os dados simulados com aqueles obtidos a campo, foi escolhida uma área de solo em nivel onde se removeu a vegetaça e foi aplicado a água. A umidade do solo no bulbo molhado foi determinada 24, 48, e 72 horas, após o inicio da aplicaçăo d’água. 0 método utilizado foi o gravimétrico, onde as amostras 


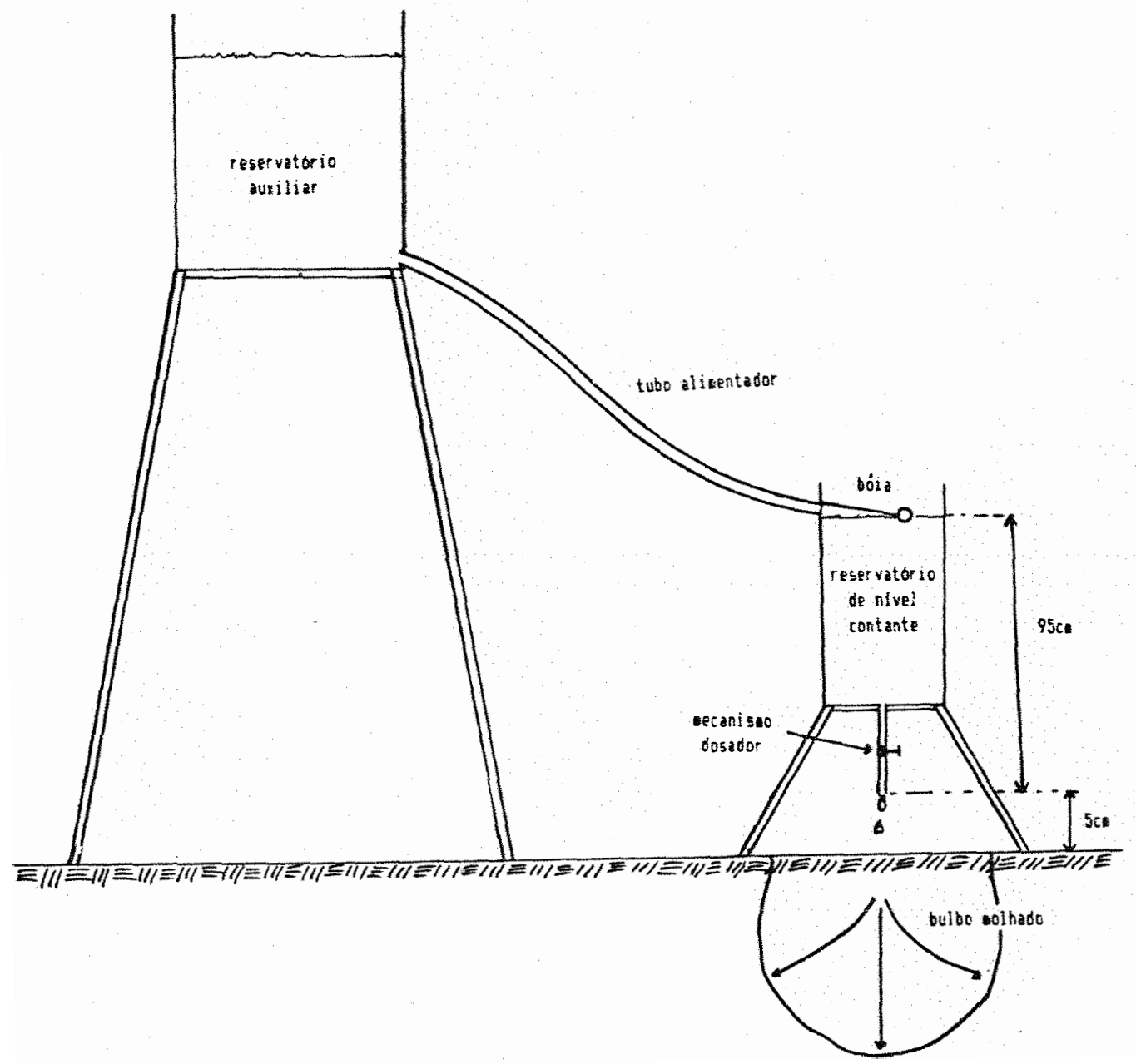

Figura 1 - Esquema do mecanismo de suprimento d'água. 
foram obtidas com o auxilio de um trado tubular (trado de VIMHEYER, e acondicionadas em cápsulas metálicas com tampa, e logo após a coleta estas cápsulas, devidamente com - solo, foram pesadas e levadas a estufa a temperatura de 105 a 110 graus até peso constante, onde por diferenca entre o peso úmido e o peso seco obteve-se as umidades. A Figura 2, mostra esquematicamente o solo dividido em anéis concentricos, tendo 'como centro a fonte puntiforme. As amostras foram obtidas, a cada $10 \mathrm{~cm}$ ao longo de dois raios do circulo formado pelos aneis, e a cada $10 \mathrm{~cm}$ de profundidade, de modo que todo anel esquenatizado foi amostrado por duas vezes. 0 total de raios amostrados foram 6 ( 2 para cada tempo), dispostos de modo a formar na superficie do solo angulos de 60 graus, pois assim o bulbo molthado foi dividido em 6 fatias de igual tamanho.

\subsection{SIMULACỸ̄O DOS DADOS}

Um modelo para simulaçăo foi codificado em linguagem basic, para estimar a distribuiça de água no bulbo molhado pela fonte puntiforme. Este modelo baseou no exposto por VAN DER PLOEG e BENECKE (1974), associado a metodologia exposta por VAN GENUCHTEN (1980), para obter a condutividade hidráulica relativa a partir da curva de retença de água. 


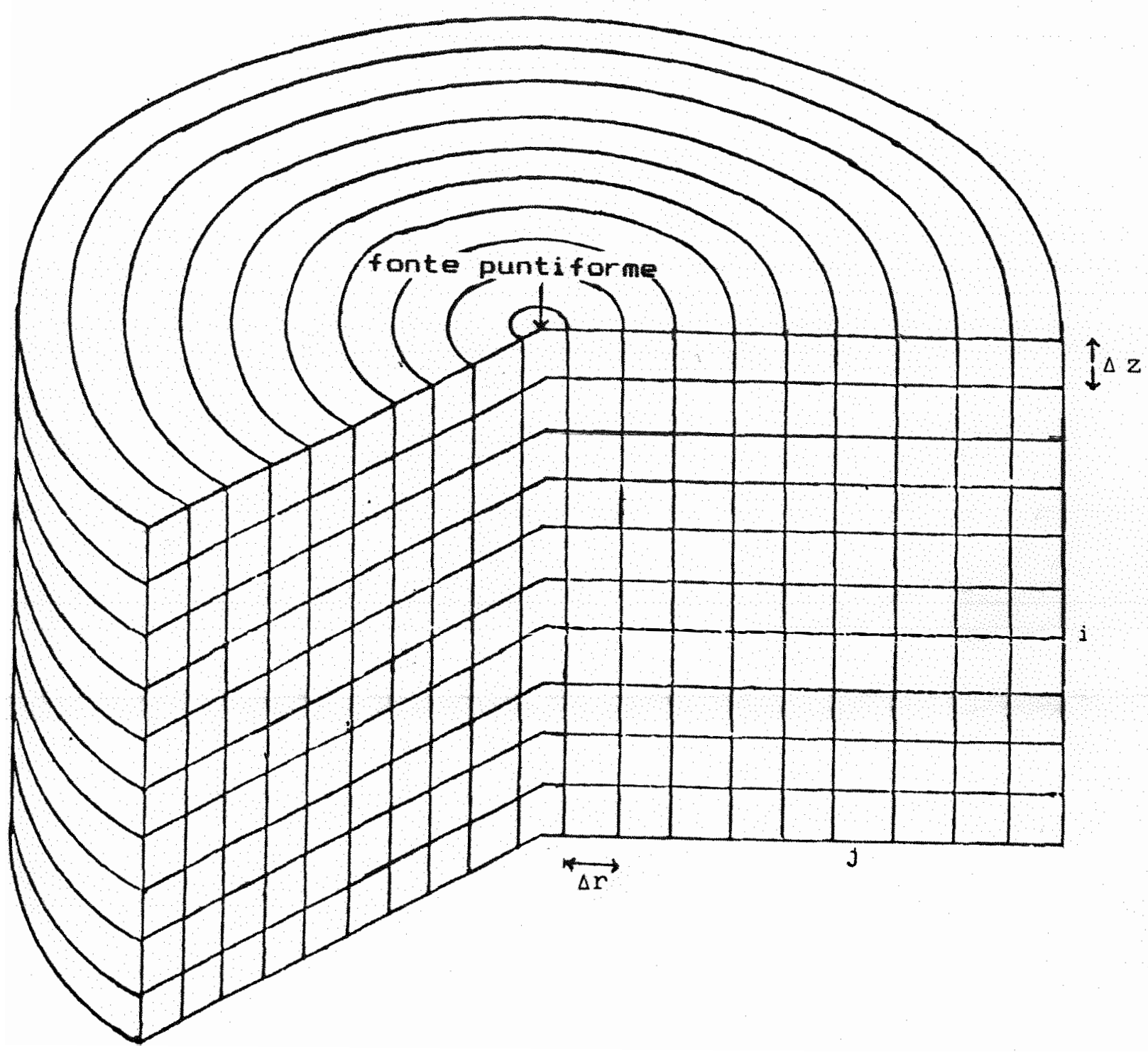

Figura 2 - Esquema dos anéis concentricos, utilizados no desenvolvimento do modelo para simulaçáo da distribuicão espacial da égua no solo. 
0 solo foi imaginariamente dividido em anéis, cada um com largura $\Delta r \mathrm{e}$ profundidade $\Delta z$. Os anéis tinham como centro uma linha vertical que partia da fonte puntiforme na superficie do solo como é ilustrado na Figura 2. Considerando o Indice "i" como endereço do anel ao longo da profundidade, e o Indice " $j$ " como endereço do anel em relaçăo ao raio, podemos calcular a densidade de fluxo horizontal de um anel a outro aplicando a equaça de Darcy, sendo:

$q(i, j-1$ a $i, j)=-k(i, j-1$ a $i, j) \frac{H(i, j)-H(i, j-1)}{\Delta r}$

onde:

$$
\begin{aligned}
q(i, j-1 \text { a } i, j)= & \text { densidade de fluxo através da } \\
& \text { interface } i, j-1 \text { a } i, j \text {, em cm/h; } \\
k(i, j-1 \text { a } i, j)= & \text { condutividade hidráulica média } \\
& \text { entre o anel da posiço } i, j-1 \text { e o } \\
& \text { da posiçăo } i, j, \text { em cm/h; }
\end{aligned}
$$

$H(i, j)=$ potencial hidráulico total da água do anel da posiçăo $i, j$, em cm de coluna d’água;

$H(i, j-1)=$ potencial hidráulico total da água do anel da posiçơ $i, j-1$, em cm de coluna d’água;

$\Delta r=$ diferença entre o raio dos dois anéis em cm.

A densidade de fluxo no sentido vertical, foi calculada de maneira análoga a equaça 4 , onde os 
Indices $i, j-1$ foram substituidos por $i-1, j e$ p $p$ or $\Delta z$.

o volume de água que passou horizontalmente de um anel a outro, pode ser calculado pela expressåa a seguir:

$V(i, j-1$ a $i, j)=q(i, j-1$ a $i, j) . \Delta z \cdot 2 \pi r(i, j) \Delta t$

sendo:

$$
\begin{aligned}
& V(i, j-1 \text { a } i, j)=\text { volume de água que } f \circ i \text { do anel } \\
& \qquad i, j-1 \text { ao anel } i, j, \text { em cm } ; \\
& \Delta z=\text { altura do anel, em cm; } \\
& r(i, j)=\text { raio interno do anel da posicăo } i, j \text {, em cm; } \\
& \Delta t=\text { intervalo de tempo, em segundos. }
\end{aligned}
$$

- volume de água que passou verticalmente de um anel a outro foi calculado pela seguinte expressåa: $V(i-1, j$ a $i, j)=q(i-1, j a i, j)=2 \pi[r(i+1, j)-r(i, j)] . \Delta t$

sendo:

$$
\begin{aligned}
& V(i-1, j \text { a } i, j)=v o l u m e \text { de água que foi do anel } \\
& i-1, j \text { ao anel } i, j \text {, em cm ; } \\
& r(i+1, j)=\text { raio externo do anel da posiço } i+1, j \text {, } \\
& \text { em cm; } \\
& r(i, j)=\text { raio interno do anel da posiçăo } i, j \text {, em cm. } \\
& \Delta t=\text { intervalo de tempo, em segundos. }
\end{aligned}
$$

A quantidade de água que permaneceu em um determinado anel, foi obtida pela diferença entre a 
quantidade de água que entrou e a quantidade de água que deixou este anel, como podemos expressar a seguir:

$$
\begin{aligned}
\Delta V(i, j)= & V(i, j-1 \text { a } i, j)+V(i-1, j a i, j) \\
& -v(i+1, j a i, j)-V(i, j+1 \text { a } i, j)
\end{aligned}
$$

sendo:

$$
\begin{aligned}
& \Delta V(i, j)=\text { varią̧ăo no volume de água do anel } i, j \text {, em } \\
& 3 \\
& \text { cm ; } \\
& V(i-1, j a j, j)=\text { volume de água que chegou ao anel } \\
& i, j \text { pela posiçăo } i-1, j \text {, en } \mathrm{cm}^{3} \text {; } \\
& V(i, j-1 \text { a } i, j)=\text { volume de água que chegou ao anel } \\
& i, j \text { pela posiçăo } i, j-1 \text {, em } \mathrm{cm}^{3} \text {; } \\
& V(i+1, j \text { a } i, j)=\text { volume de água que dei } \mathbf{i} \text { ou o anel } \\
& i, j \text { pela posiçăo } i+1, j \text {, em cm ; } \\
& V(i, j+1 \text { a } i, j)=\text { volume de água que deixou o anel } \\
& i, j \text { pela posiçăo } i, j+1 \text {, em cm ; }
\end{aligned}
$$

A curva caracteristica foi representada pela equaçăo descrita por VAN GENUCHTEN (1980). A equaça é a seguinte:

$$
\phi=\left(\frac{1}{1+(\alpha h)^{n}}\right)^{m}
$$

sendo:

$$
\phi=\text { umidade admensional, dada por: } \frac{\theta-\theta r}{\theta s-\theta r}
$$


onde:

$$
\begin{aligned}
& \theta=\text { umidade volumetrica, em } \mathrm{cm}^{3} / \mathrm{cm}^{3} \text {; } \\
& \theta_{r}=\text { umidade volumetrica residual (umidade obtida sob } \\
& \text { tensao de } 15 \text { atmosferas), em cm / cm } 3 \\
& \theta_{s}=\text { umidade volumétrica de saturaçă, em cm / cm; } \\
& h \text { = potencial matricial da água no solo, em cm de } \\
& \text { coluna d’água; } \\
& \alpha=\text { parametro do solo, em } \mathrm{cm}^{-1} \text {; } \\
& \text { n e m = parametros do solo, admensionais. }
\end{aligned}
$$

A equaça 8 , foi substituida por VAN GENUCHTEN (1980) em um modelo para obtençăo da condutividade hidráulica relativa, descrito por MUALEM (1976), tendo resultado a seguinte expressao:

$$
\operatorname{kr}(\phi)=\phi^{1 / 2}\left(1-\left(1-\phi^{1 / m}\right)^{m}\right)^{2}
$$

onde $\operatorname{Kr}(\phi)$ é a condutividade hidráulica relativa, e os outros parametros tem o mesmo significado apresentados na equaçัo B. A condutividade hidráulica relativa é a relaçăo entre a condutividade hidráulica na umidade considerada, e a condutividade hidráulica saturada, ou seja:

$$
k r=\frac{k(\theta)}{k(0)}
$$


onde:

$$
\begin{aligned}
K r= & \text { condutividade hidráulica relativa, em cm/h; } \\
K(\theta)= & \text { condutividade hidráulica na umidade } \\
& \text { considerada, em cm/h; } \\
K(0)= & \text { condutividade hidráulica saturada em cm/h. }
\end{aligned}
$$

Seguindo a teoria exposta, foi desenvolvido a fluxograma mostrado na Figura 3 , e tambem um programa em linguagem basic para microcomputador da linha IBM-PC, onde simulou a distribuiço espacial da água, em solo irrigado com gotejador. 


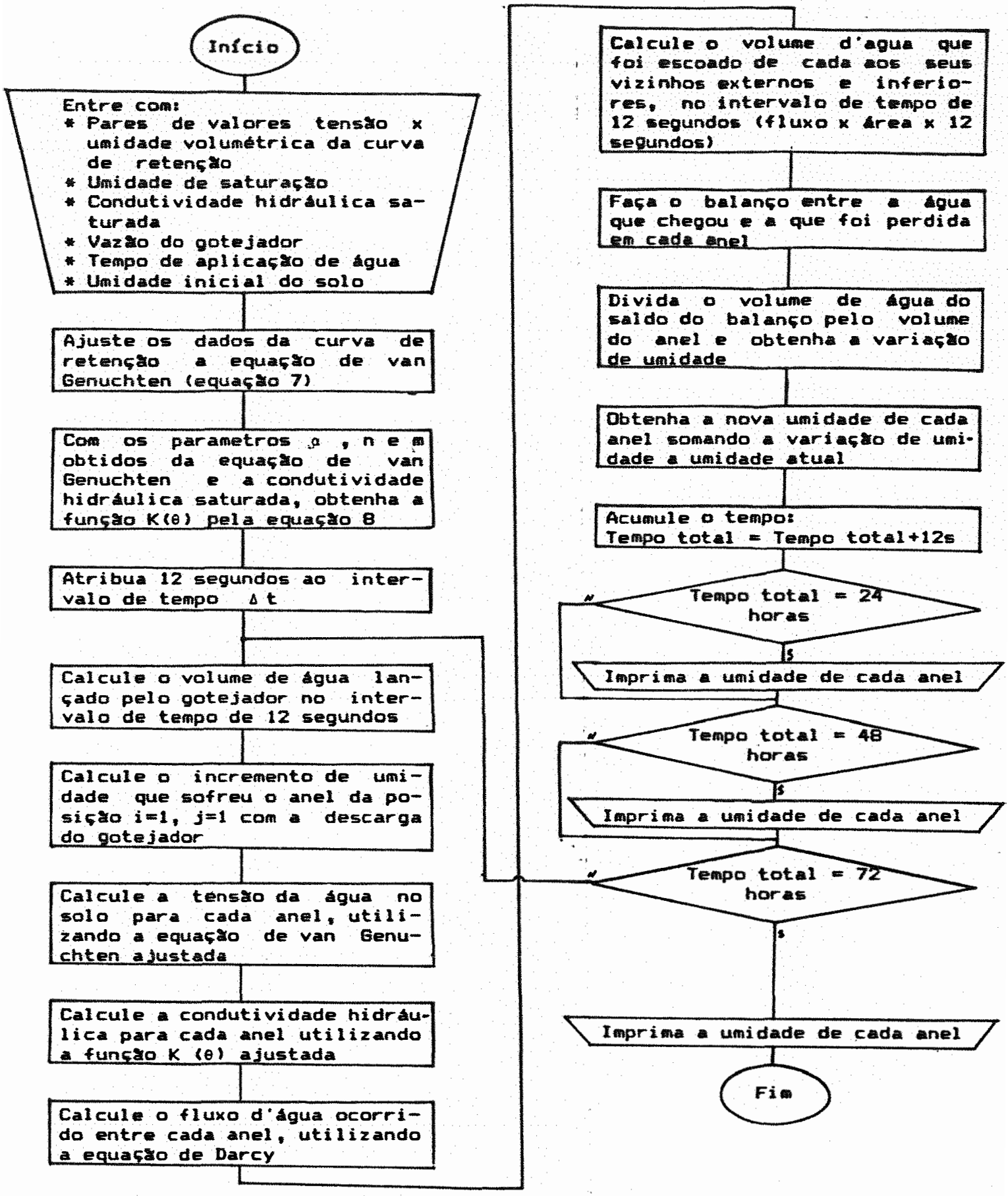

Figura 3. - Fluxograma utilizado no desenvolvimento do programa para simulaça dos dados 
4 - Resultados e discussão

4.1 - Curva de retençăo, condutividade hidráulica e ajuste das equaç8es.

Na Tabela 2, estao apresentados os pares de valores de tensăo versus umidade volumétrica para os perfis amostrados, e na Tabela 3 , estao apresentados os parametros de ajuste destes dados a eq. (8).

É usual em regressôes lineares representar o grau de ajuste das equaçores pelos coeficientes de determinaçăo e pelos coeficientes de correlaçăo, porém em ajustes a equaçôes nåo lineares como é o caso da eq. (8) estes coeficientes nåo, săo mais válidos. Utilizou-se outro parametro para medida do grau de ajuste da eq. (8) aos dados experimentais, que foi obtido pela relaçăontre a soma dos quadrados dos desvios da regressáo e a soma de 
quadrados totais subtraidos da unidade, chamado na Tabela 3 de ajuste; quanto mais próximo da unidade far este coeficiente, melhor o ajuste, isto e, menor serao os desvios da regressăo.

Tabela 2 - Tensa versus umidade volumetrica (\%) para as diferentes profundidades.

$$
\text { profun- tensao em centimetros de coluna d'agua }
$$

di dade

(cm) sat $10 \quad 40 \quad 200 \quad 500 \quad 1000 \quad 5000 \quad 15000$

$\begin{array}{rlllllllllll}0-20 & 34,0 & 32,2 & 28,8 & 17,2 & 14,0 & 13,5 & 12,5 & 12,0 \\ 20-40 & 32,5 & 30,4 & 25,8 & 18,8 & 15,3 & 14,0 & 12,5 & 12,0 \\ 40-60 & 36,5 & 33,8 & 27,3 & 19,3 & 16,0 & 14,2 & 12,5 & 12,1 \\ 60-80 & 36,8 & 33,9 & 27,4 & 18,0 & 15,1 & 14,0 & 11,9 & 11,3 \\ 80-100 & 37,9 & 34,8 & 27,2 & 16,4 & 12,6 & 11,6 & 10,6 & 10,3\end{array}$

Observa-se pelos coeficientes de ajuste apresentados na Tabela 3 e também pelas Figuras de 4 a 8 , a seguir, que mostram, respectivamente, para as profundidades de 0 a 20,20 a 40,40 a 60,60 a 80 e 80 a $100 \mathrm{~cm}$, a representaça grafica das equaçßies juntamente 


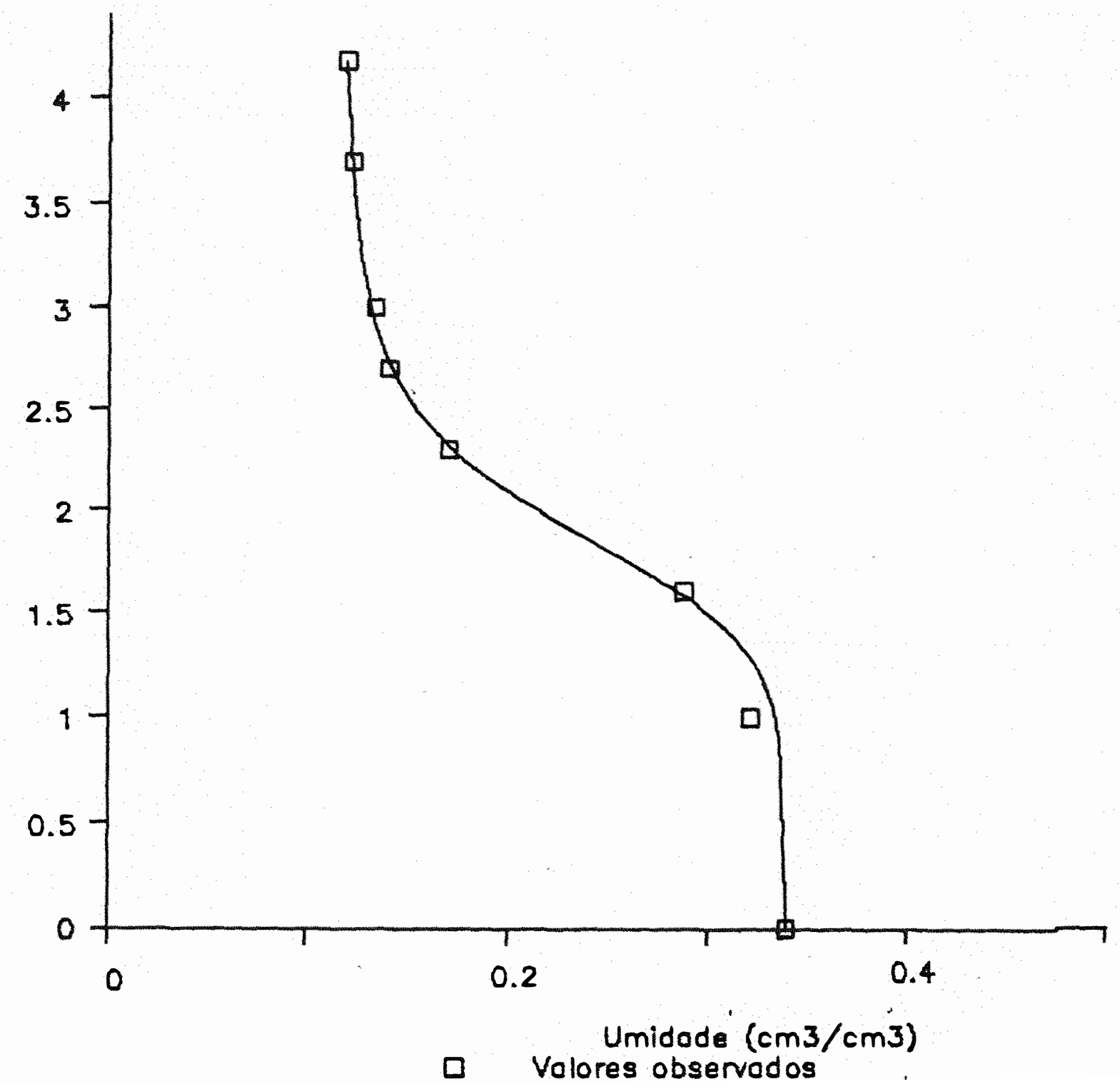

Figura 4 - Representaçăo gráfica da equaçăo da curva de retença e dados experimentais, para a profundidade de 0 a $20 \mathrm{~cm}$. 
O

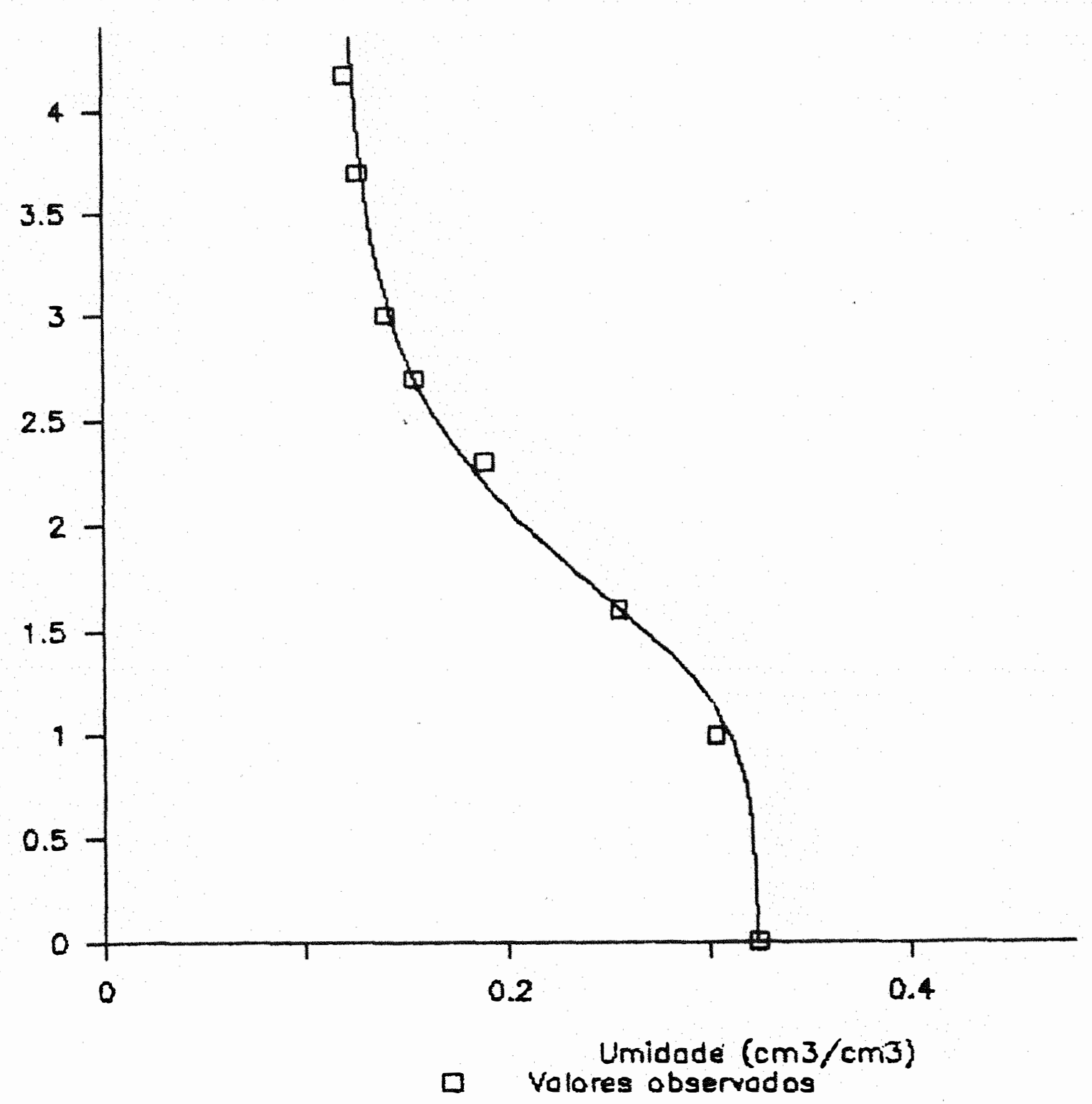

Figura 5 - Representaçăo gráfica da equaço da curva de retenço e dados experimentais, para a profundidade de 20 a $40 \mathrm{~cm}$. 


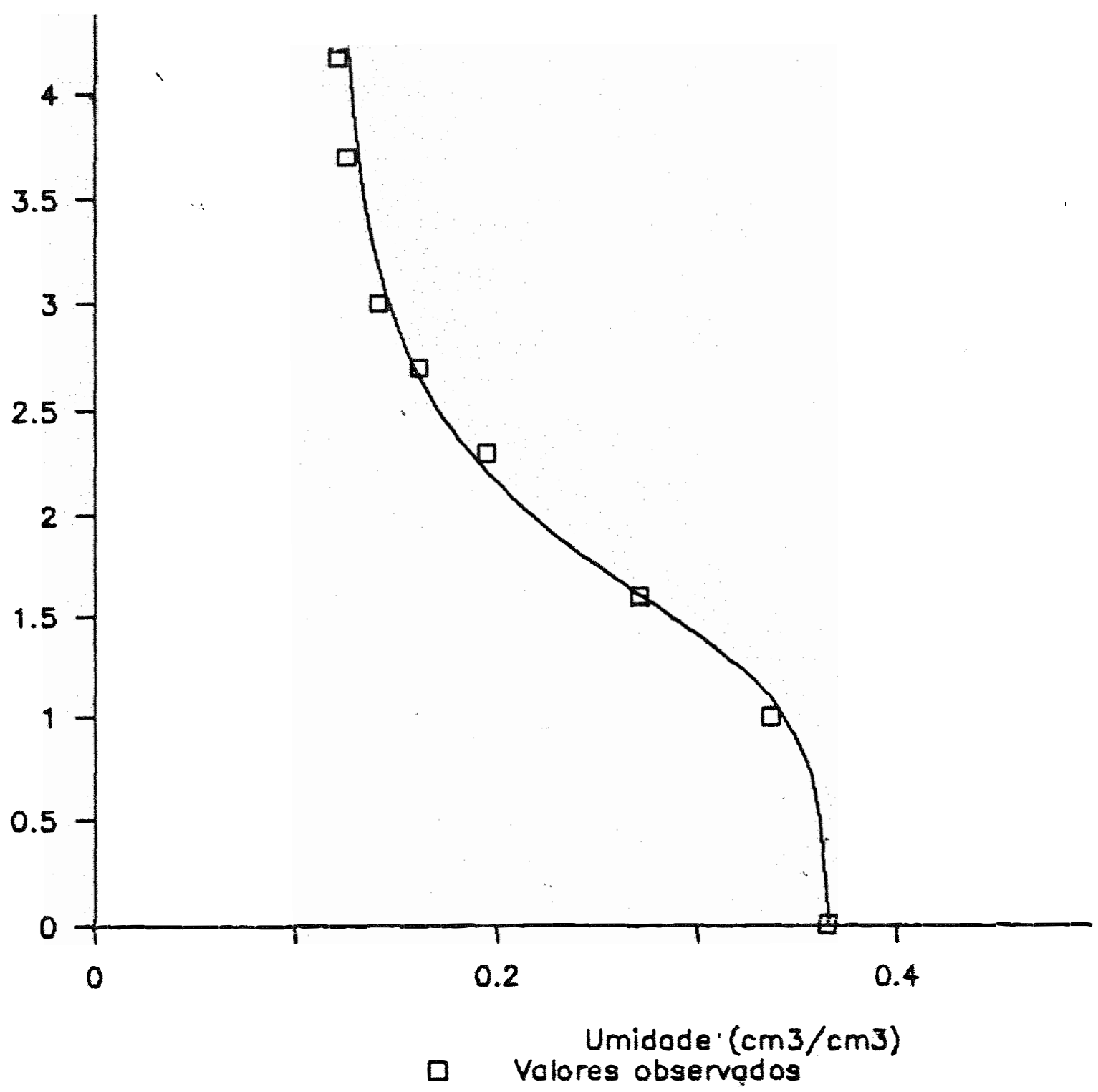

Figura 6 - Fepresentaça gráfica da equaçăo da curva de retença e dados experimentais, para a profundidade de 40 a $60 \mathrm{~cm}$. 


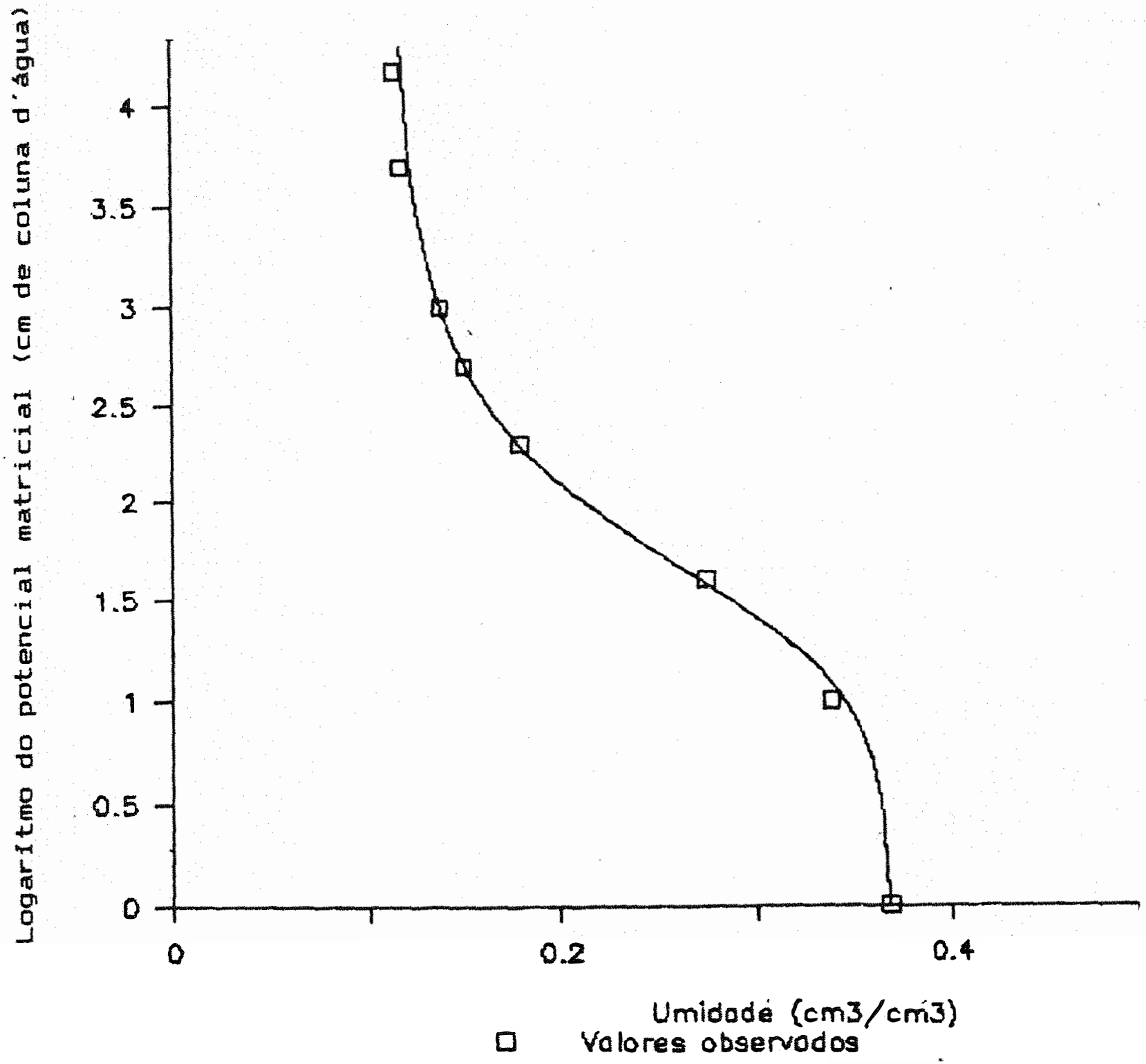

Figura 7 - Representaçăo gráfica da equaçăo da curva de retença e dados experimentais, para a profundidade de 60 a $80 \mathrm{~cm}$. 


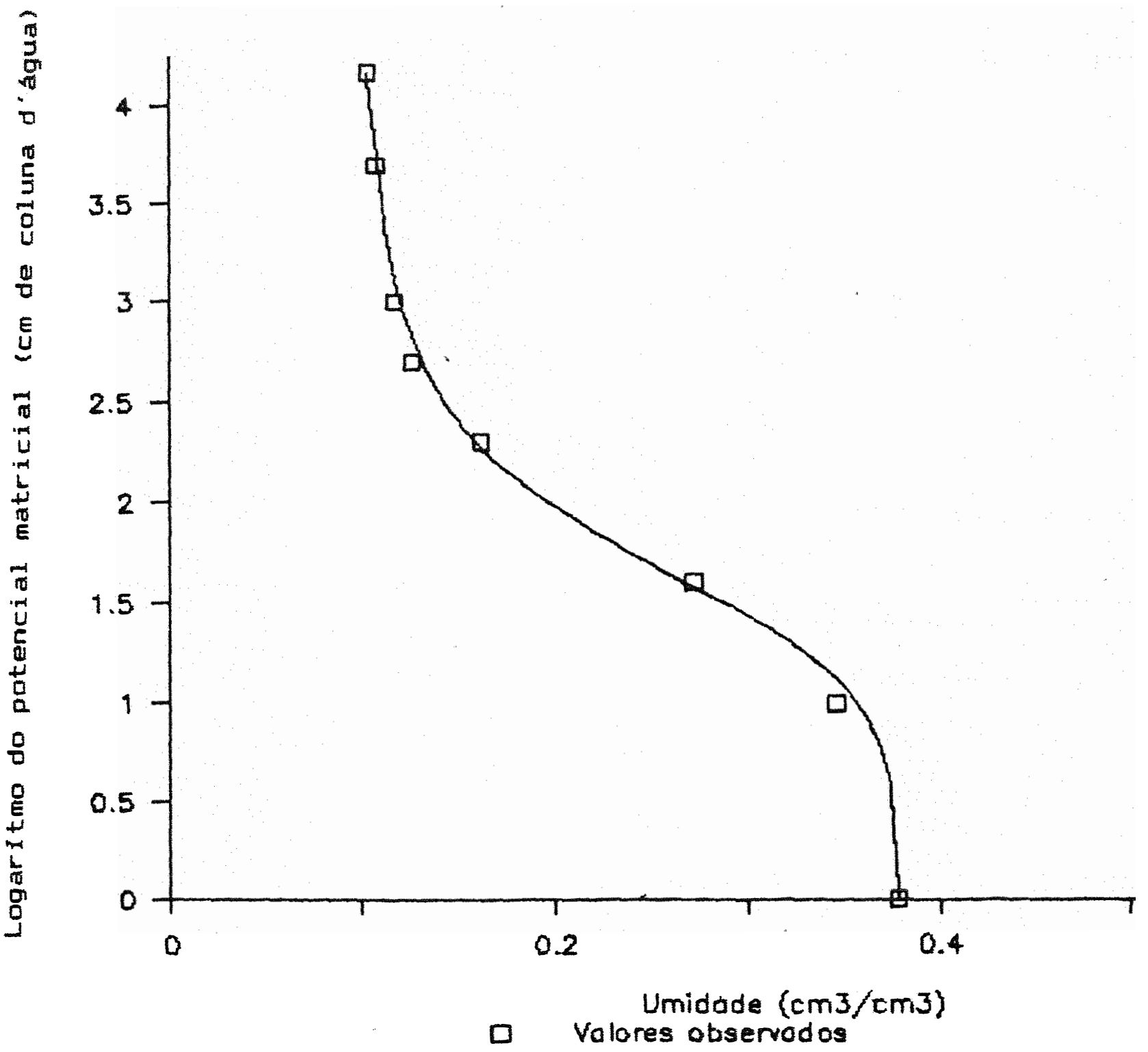

Figura 8 - Representaçăo gráfica da equaça da curva de retença e dados experimentais, para a profundidade de 80 a $100 \mathrm{~cm}$. 
com os dados experimentais, que o modelo de equaçăo escolinido eq. (8) se ajustou bem aos dados experimentais. Utilizando-se dos parkmetros $\alpha, n \in m_{y}$ mostrados na Tabela 3, onde foram obtidos pelo ajuste dos dados da curva de retencăo a eq. (8), foi possivel obter a condutividade hidráulica relativa através da eq. (9). Utilizando-se da condutividade Midráulica relativa e da condutividade hidráulica saturada, apresentada na Tabela 4, foi possivel estimar a condutividade ridráulica en funçăo da umidade, isto $e, k(\theta)$.

Tabela 3 - Parámetros de ajustes das curvas de retença da áqua no solo a eq. (8).

profun-
didade
$\alpha$
n
m
ajuste

(cm)

$\begin{array}{rrrrr}0-20 & 0,022554 & 1,927006 & 0,481060 & 0,997 \\ 20-40 & 0,037244 & 1,605782 & 0,377250 & 0,996 \\ 40-60 & 0,045748 & 1,588359 & 0,370419 & 0,998 \\ 60-80 & 0,045195 & 1,602454 & 0,375957 & 0,998 \\ 80-100 & 0,040337 & 1,751652 & 0,429110 & 0,997\end{array}$


Tabela 4 - Condutividade hidráulica saturada, densidade global e umidade inicial das diferentes camadas.

$\begin{array}{clll}\text { Profundidade } & \begin{array}{c}\text { condutividade } \\ \text { hidraulica }\end{array} & \text { global } & \text { umidade } \\ (\mathrm{cm}) & \text { saturada(cm/h) } & \text { (g/cm3) } & \text { inicial }\end{array}$

$\begin{array}{lllll}0-20 & 3,0 & 1,60 & 12,1 \\ 20-40 & 3,3 & 1,61 & 13,2 \\ 40-60 & 3,6 & 1,54 & 12,5 \\ 60-80 & 3,4 & 1,40 & 12,2 \\ 80-100 & 3,2 & 1,40 & 12,0\end{array}$

Além da condutividade hidráulica saturada para as diversas camadas, a Tabela 4 apresenta também, a densidade global e a umidade inicial obtida, antes da aplicaçăo de água na área experimental.

4.2 - Observaçôes de campo.

As Tabelas 5, 6 e 7 mostram, respectivamente, as umidades volumetricas percentuais, obtidas a campo para o perfil molhado pela fonte puntiforme sob 
Tabel-5-Lnidade volumbtrica (\%) observadi para o perfil de dietribuigro de agua no solo wob fonte puntiforme, com vazua de $101 / \mathrm{h}, 24$ horas apor o inleio dia a licaço d'agua.

\begin{tabular}{|c|c|c|c|c|c|c|c|c|}
\hline didade & $\cdots \cdots$ & $\cdots \cdots$ & 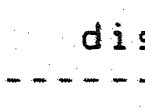 & $\begin{array}{l}\operatorname{tancia} \\
--\ldots--\end{array}$ & radia & $l_{---}(\mathrm{cm})$ & -- & \\
\hline$(c m)$ & 0 & 10 & 20 & 30 & 40 & 50 & 60 & 70 \\
\hline------ & 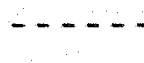 & $\because$ & $\cdots-\cdots$ & $\therefore$ & 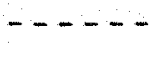 & $x$ & 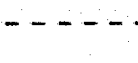 & $\ldots$ \\
\hline $0-10$ & 16.9 & 16.2 & 17.7 & 16.8 & 16.8 & 15.5 & 8.9 & 7.8 \\
\hline $10-20$ & 15.6 & 20.2 & 18.9 & 19.9 & 18.9 & 17.3 & 11.6 & 9.9 \\
\hline $20-30$ & 21.5 & 21.9 & 22.3 & 20.9 & 21.0 & 18.5 & 15.3 & 12.2 \\
\hline $30-40$ & 21.2 & 21.3 & 21.8 & 20.5 & 20.1 & 18.7 & 13.5 & 13.5 \\
\hline $40-50$ & 18.8 & 18.6 & 17.8 & 17.1 & 15.2 & 14.0 & 13.0 & 12.7 \\
\hline $50-60$ & 16.5 & 16.5 & 15.8 & 17.1 & 12.7 & 13.7 & 11.9 & 13.3 \\
\hline $60-70$ & 12.7 & 12.8 & 11.6 & 12.2 & .11 .9 & 12.0 & 11.5 & 11.8 \\
\hline $70-80$ & 9.7 & 11.8 & 12.4 & 12.1 & 12.2 & 11.9 & 11.8 & 11.8 \\
\hline $80-90$ & 11.2 & 12.7 & 12.4 & 11.9 & 13.1 & 11.5 & 12.3 & 11.9 \\
\hline $90-100$ & 11.4 & 12.5 & 12.4 & 12.3 & 12.3 & 12.2 & 12.3 & 11.5 \\
\hline
\end{tabular}


Tabela 6 - Umidade volumetrica $(\%)$ observada para o perfil de distribuigao de água no solo sob fonte puntiforme, com vazao de $101 / \mathrm{h}, 48$ horas após o inicio da aplicaço d'agua.

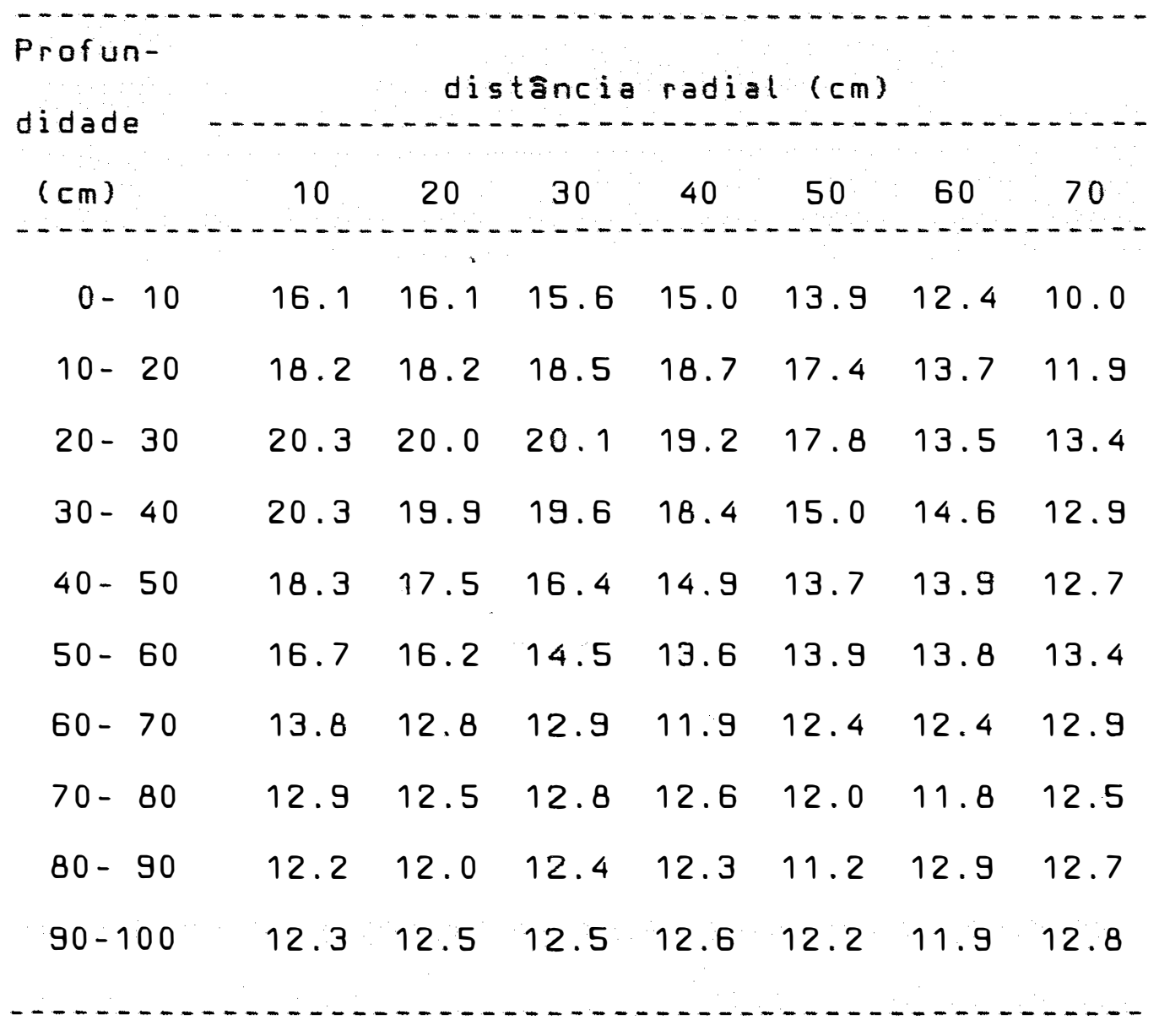


Tabela 7 - Umidade volumetrica (\%) observada para o perfil de distribuiço de água no solo sob fonte puntiforme, com vazao de $101 / \mathrm{h}, 72$ horas após o infcio da aplicaço d’água.

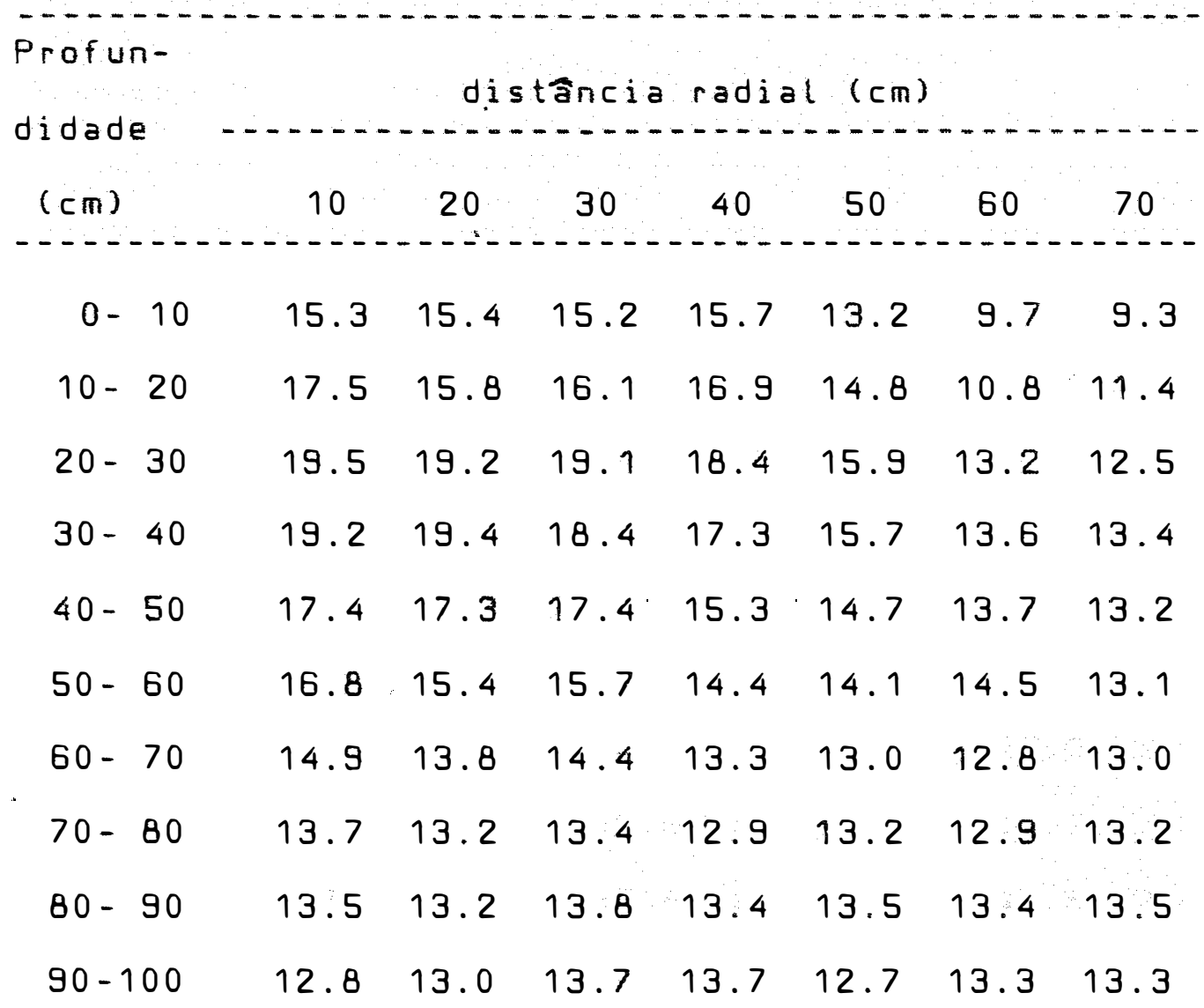


vazåo de $101 / \mathrm{h}, 24,48$ e 72 horas, após o inicio da aplicaço d’agua. Observa-se que há valores de umidade que fogem a tendencia mostrada pelos demais, o que em condiçes de campo, isto, normalmente ocorre, sendo atribuido ao fato de que os solos apresentam variaçoses ao longo de seu perfil, fato este que tem despertado interesse em muitos pesquisadores, e vários trabalios sobre o estudo da variabilidade espacial de solos tem surgido nas literaturas especializadas, recentemente.

Paraminimizar o efeito das variaçoes de umidade, foram elaboradas as Tabelas 8, 9 e 10 a partir das Tabelas 5, 6 e 7, sendo que as umidades ao 1 ongo das distancias radiais, foram obtidas das medias das duas umidades adjacentes, ou seja, a umidade a distância radial de $5 \mathrm{~cm}$ foi obtida a partir da média entre as umidades as distancias de 0 e $10 \mathrm{~cm}$ a umidade a distancia radial de $25 \mathrm{~cm}$, foi obtida a partir da média entre as umidades as distâcias de 20 e $30 \mathrm{~cm}$, e assim sucessivamente. Procedimento identico foi feito também, para a profundidade, sendo que á umidade a profundidade de 0 a 20 cm, foi obtida da média da umidade de 0 a $10 \mathrm{~cm}$ e 10 a 20 cm. Deste modo, cada umidade apresentada nas Tabelas 8, 9 e 10 foram obtidos da média de 8 determinaç8es a campo, 0 que dilui variaçŏes provinientes da variabilidade espacial do solo, ou mesmo de imprecisbes nas determinaçbes.

Para os tempos de 48 e 72 horas, nao foi 
Tabela 8 - Umidade volumetrica média (\%) observada para 0 perfil de distribuicăo de agua no solo sob fonte puntiforme, com vazao de $101 / \mathrm{h}, 24$ horas após o inicio da aplicasaro d’água.

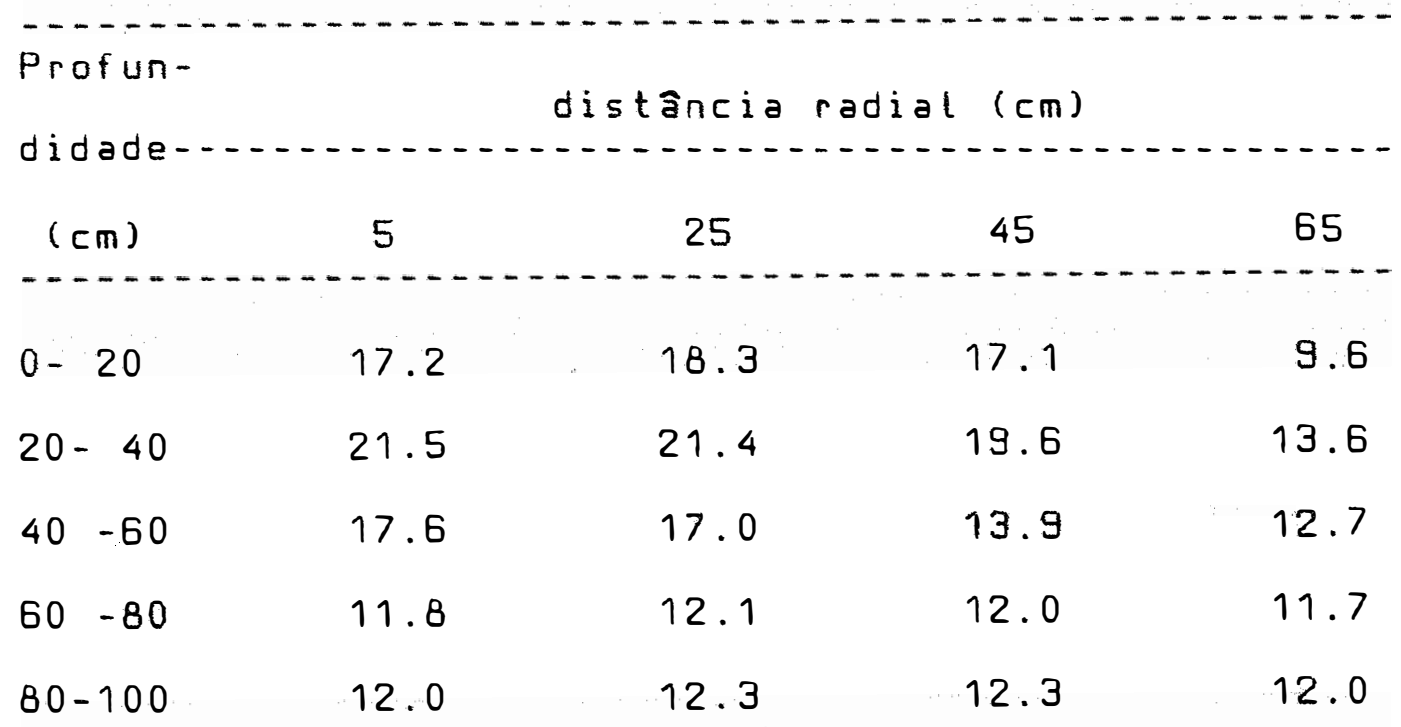


Tabela 9 - Umidade volumetrica media (\%) observada para 0 perfil de distribuiça de água no solo sob fonte puntiforme, com vazao de $101 / \mathrm{h}, 48$ horas após o inficio da aplicação d’água.

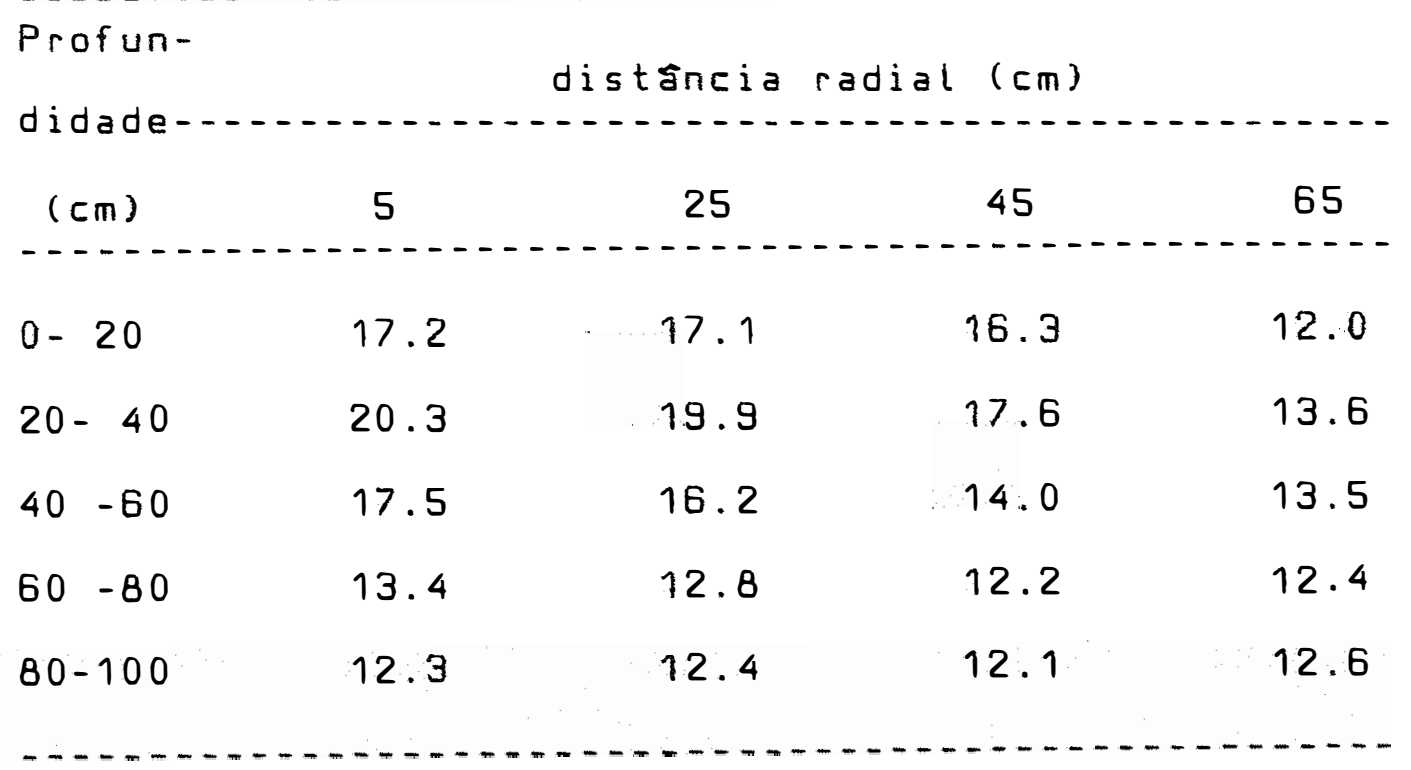


Tabela 10 - Umidade volumetrica media (\%) observada para 0 perfil de distribuiça de água no solo sob fonte puntiforme, com vazao de $101 / \mathrm{h}, 72$ horas após o inicio da aplicaçao d’água.

\begin{tabular}{|c|c|c|c|c|}
\hline \multicolumn{5}{|c|}{ 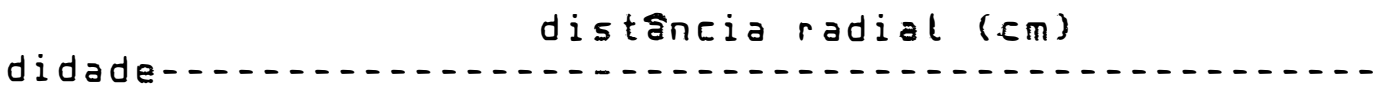 } \\
\hline$(c m)$ & 5 & 25 & 45 & 65 \\
\hline \multicolumn{5}{|c|}{ 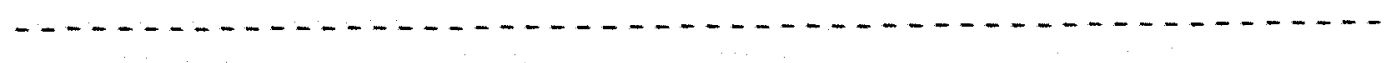 } \\
\hline $0-20$ & 16.4 & 15.6 & 15.1 & 10.3 \\
\hline $20-40$ & 19.4 & 19.0 & 16.8 & 13.2 \\
\hline $40-60$ & 17.1 & 16.5 & 14.6 & 13.6 \\
\hline $60-80$ & 14.3 & 13.7 & 13.1 & 13.0 \\
\hline $80-100$ & 13.2 & 13.4 & 13.3 & 13.4 \\
\hline
\end{tabular}


possivel obter as umidades a distancia de $0 \mathrm{~cm}$, ou seja, no centro do "bulbo" molhado, pois na primeira amostragem (de 24 horas) o solo neste ponto foi deformado pela penetrạ̧ăo do trado, porém como foi feita uma tradagem a cada $10 \mathrm{~cm}$, isto nå constituiu problema, pois a proximidade deste ponto ao subsequente nå levou a grandes variaçôes de umidade como pode ser visto na amostragem de 24 horas, - que permitiu considerar sem muito erro, a umidade deste, como sendo, também, a umidade no centro do bulbo.

Utilizando-se das Tabelas 8, 9 e 10 , foram elaboradas as Figuras 9, 10 e 11, que representam o perfil de distribuiça de umidade apresentado pelo solo submetido á fonte puntiforme com vazao de 10 litros por hora, 24,48 e 72 horas apos o inicio da aplicaçăo de água, respectivamente.

\section{3 - Dados simulados}

A simulaçæo do perfil molhado foi feita até a profundidade de 1 metro, considerando 10 perfis de $10 \mathrm{~cm}$ de profundidade cada, e uma distancia radial de um metro a partir da fonte puntiforme. Esta distancia radial foi dividida em espaços de $10 \mathrm{~cm}$, conforme a ilustraça da Figura 2. O intervalo de tempo utilizado na simulaçăo foi de 12 segundos, sendo acumulado até perfazer os tempos de 24,48 e 72 horas, apds o inficio de aplicaçăo d’água. 


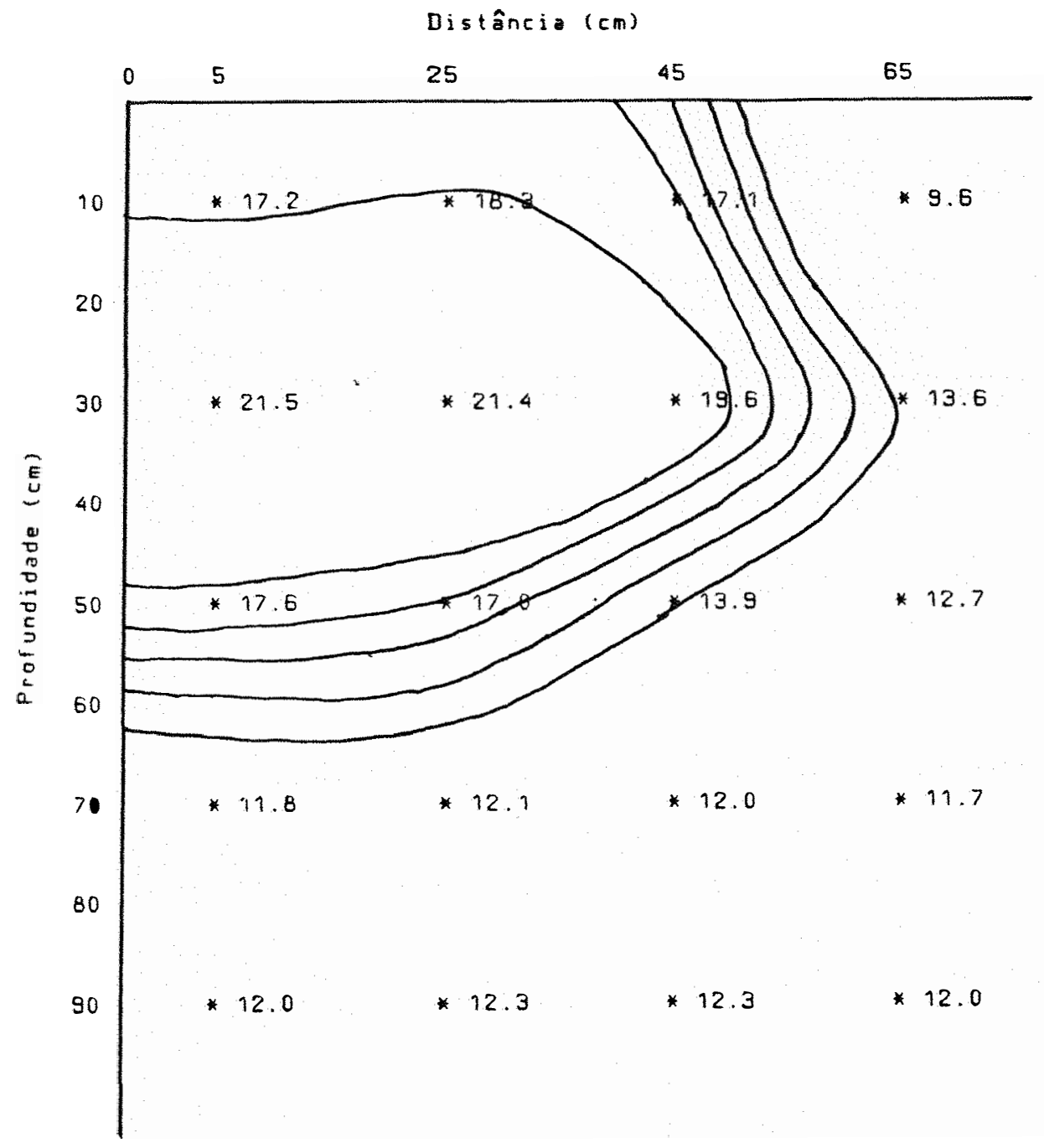

Figura 9 - Perfil de distribuicăo de unidade observado no solo: 24 horas após o inicio da aplicaçăo de água. 


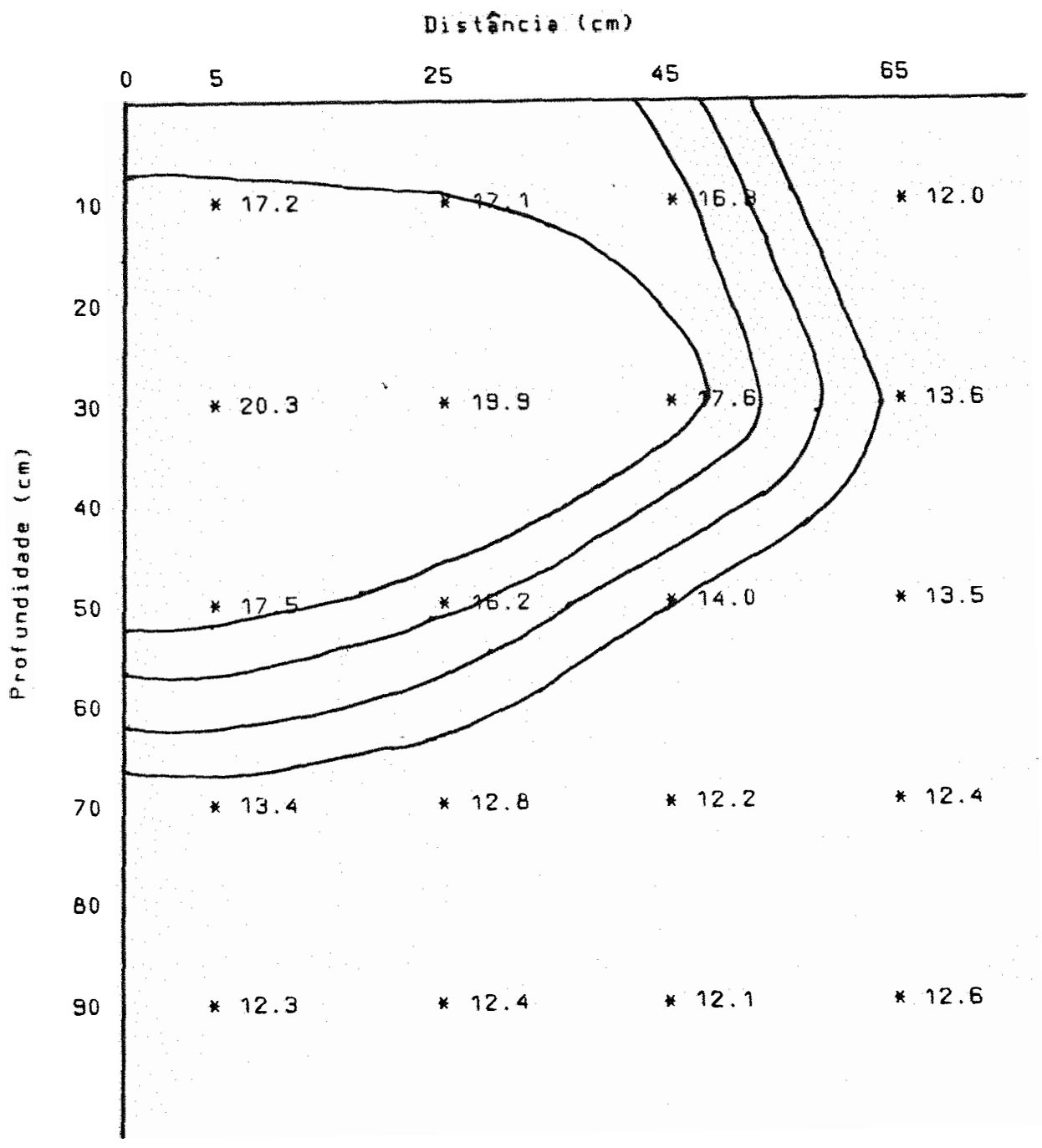

Figura 10 - Perfil de distribuicăo de umidade observado no solo, 48 horas apos o inicio da aplicaça de água. 


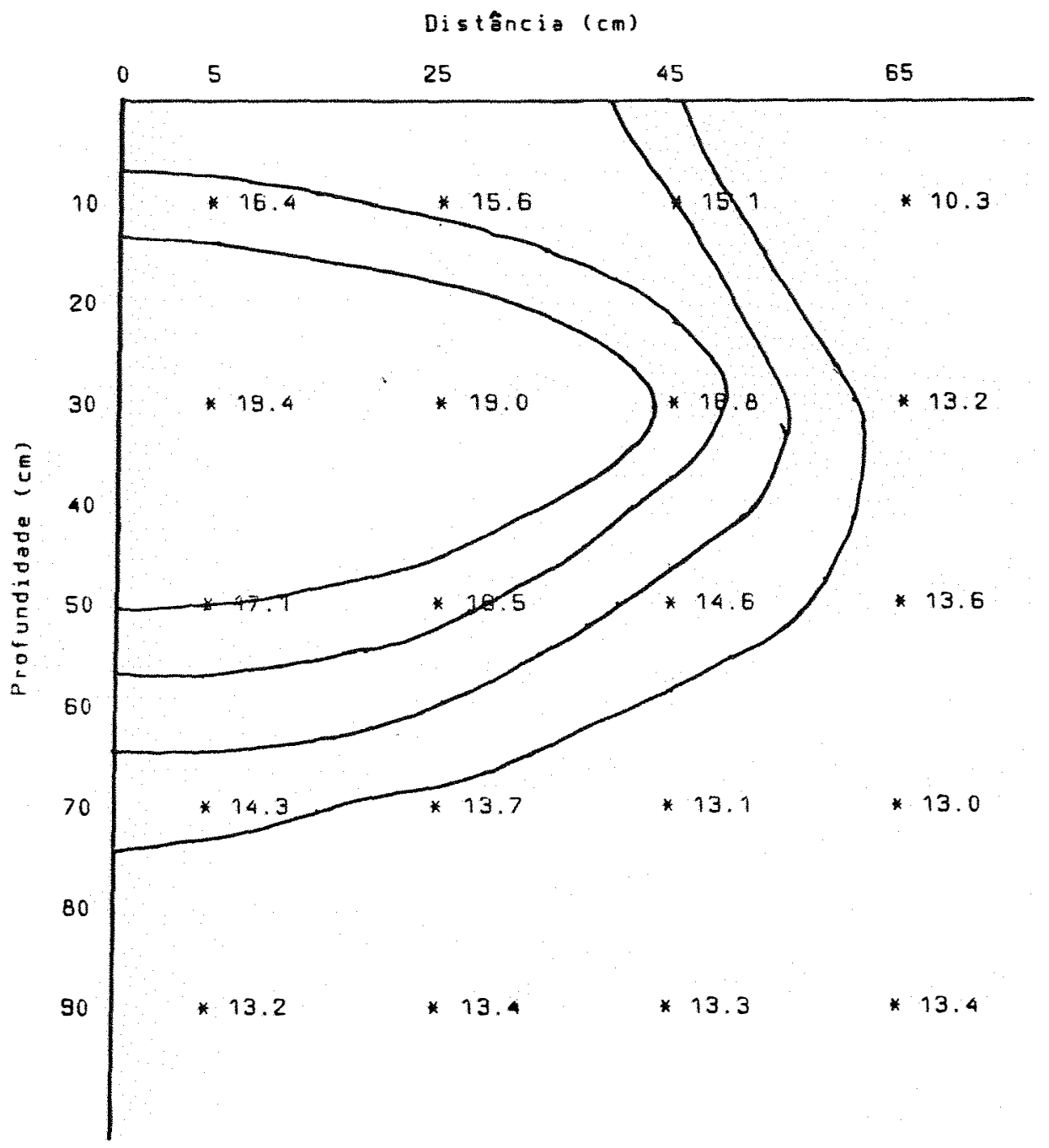

Figura 11 - Perfil de distribuicăo de umidade observado no solo, 72 horas após o inicio da aplicaça de água. 
Os dados necessários a simulaçă foram: a umidade volumetrica inicial de cada camada do solo, apresentada na Tabela 4, a umidade volumétrica de saturaçă, apresentada na Tabela 2, a umidade volumetrica residual (considerada a umidade a $15000 \mathrm{~cm}$ de coluna d'água), apresentada na. Tabela 2, os parametros $\alpha$, n e m obtidos pelo ajuste da curva de retencå a eq. (B) e apresentados na Tabela 3, a condutividade hidráulica saturada, apresentados na Tabela 4, a vazao da fonte puntiforme (10 $1 / h)$ e o tempo de aplicasag (3 horas).

Os dados obtidos pela simulaçăo, săo apresentados nas Tabelas 11,12 e 13, respectivamente, para os tempos de 24,48 e 72 horas após o inicio da aplicacăo d'água. Procurando comparar os perfis de umidade simulados com aqueles obtidos a campo, foi adotado o mesmo procedimento utilizado nos dados obtidos a campo, ou seja, utilizar as médias dos dados adjacentes para elaborar as Tabelas 14,15 e 16.

Utilizando-se das Tabelas 14,15 e 16, foram elaboradas as Figuras 12,13 e 14 , que mostram, respectivamente, o perfil de distribuifăo de umidade apresentado pelo solo submetido a uma fonte puntiforme com vazao de 10 litros por hora, $24,48, e \quad 72$ horas após o inicio da aplicaşăo de água, obtido a partir dos dados si mul ados. 


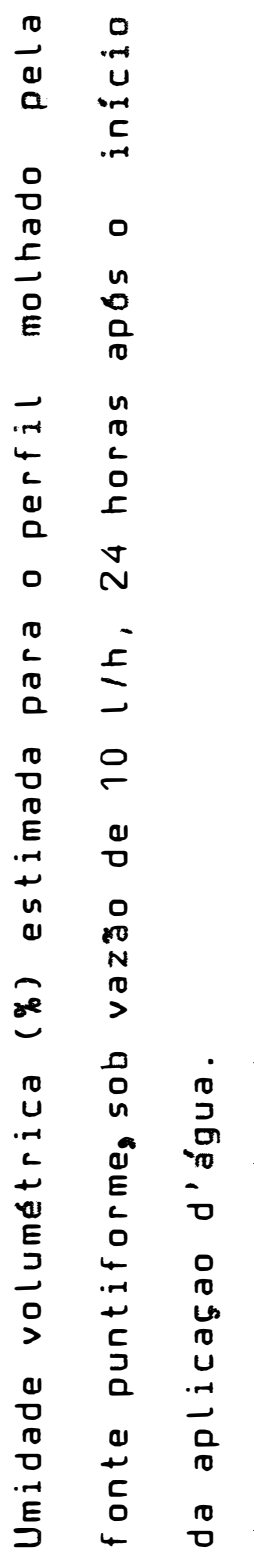

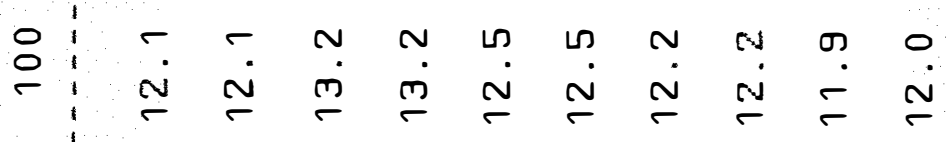

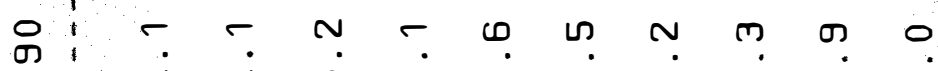

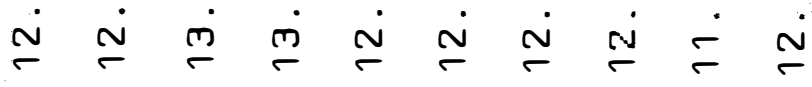

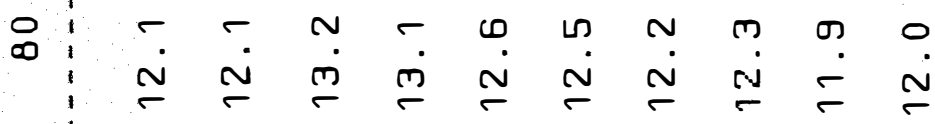

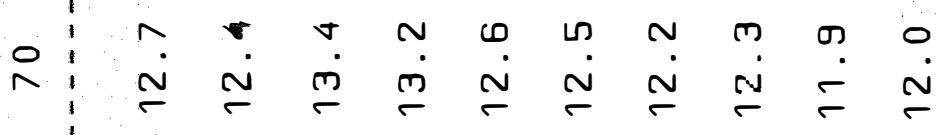

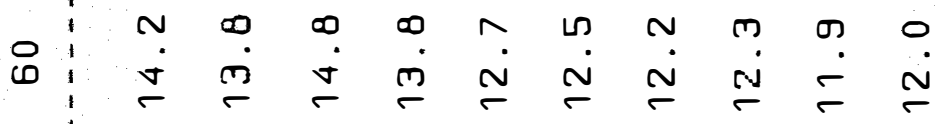

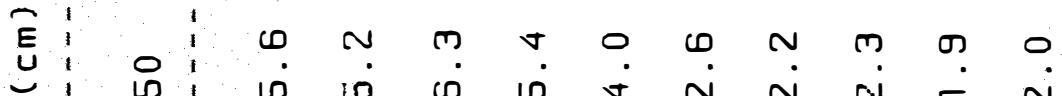

เก เ

o :

O

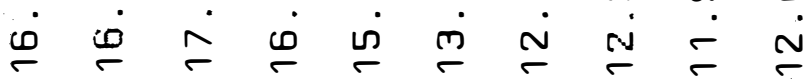

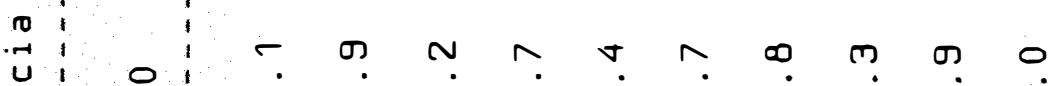
而

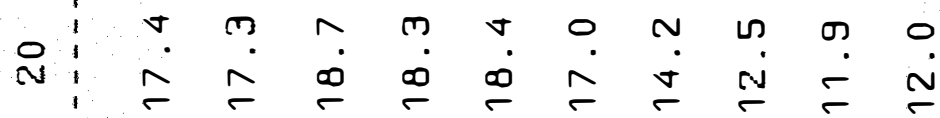

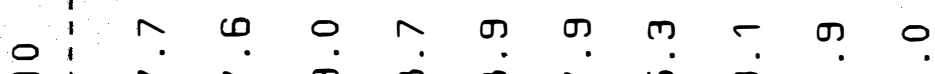

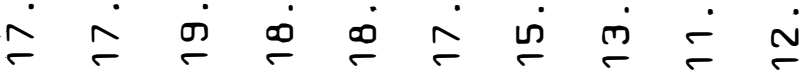

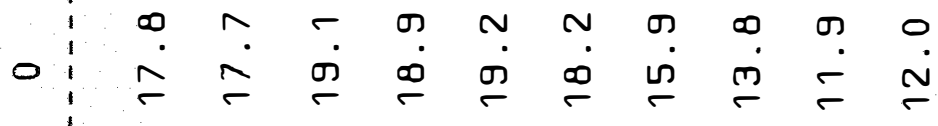

1
0
0
0
0
1

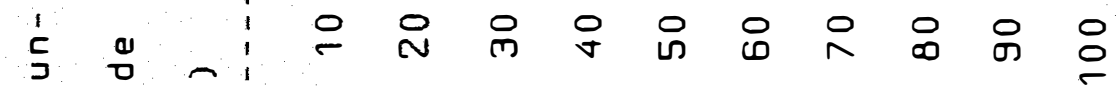

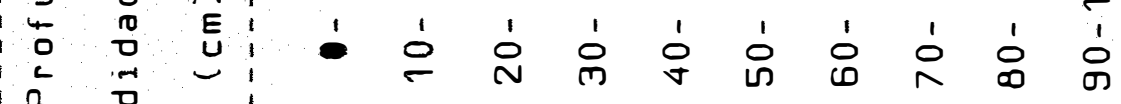


a

$\begin{array}{ll}0 & \\ 0 & 0 \\ \text { r } & n \\ 0 & 0 \\ E & 0\end{array}$

$\begin{array}{ll}= & n \\ = & 0 \\ \vdots & 0 \\ 0 & 1\end{array}$

- $\infty$

$\begin{array}{ll}0 \\ 0 & =\end{array}$

$\stackrel{0}{0} \stackrel{0}{\circ}$

$\underset{-1}{E} \frac{0}{0}$

$\begin{array}{cc}1 & 0 \\ 0 & 0 \\ 0 & 0\end{array}$

se $>$

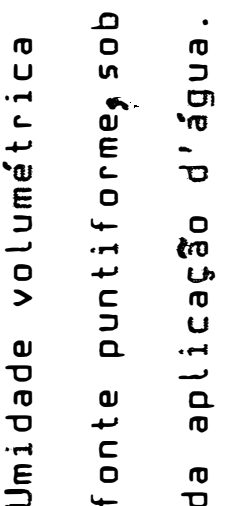

1
0
0
0
0
0

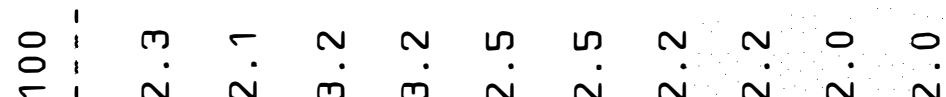

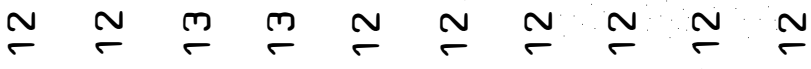

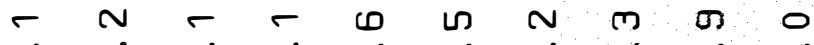

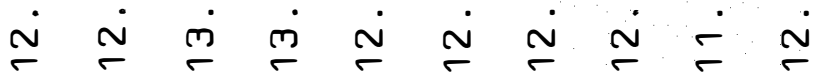

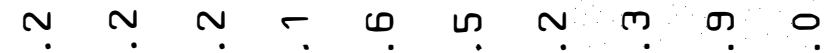

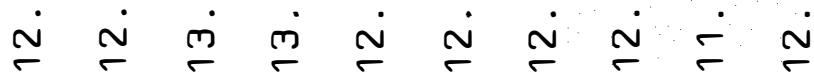

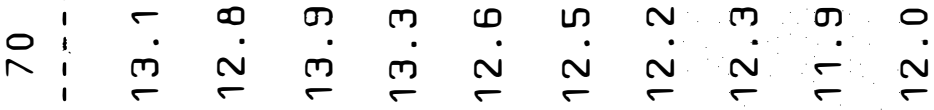

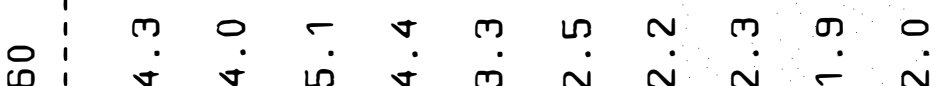

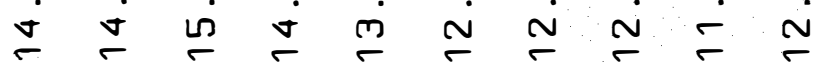

$\sim \pi \sim \pi N \infty \pi$

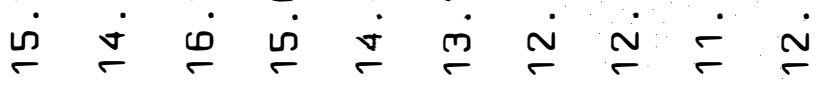
…

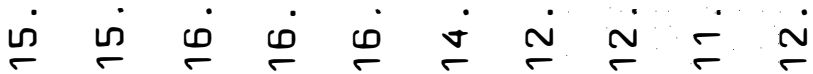
$\sim 0 \pi \sim N \sigma 0$

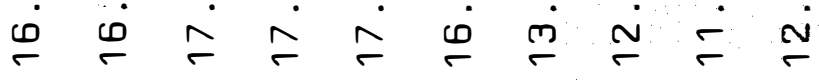

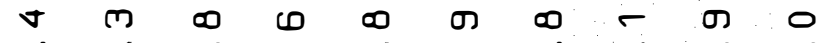
:

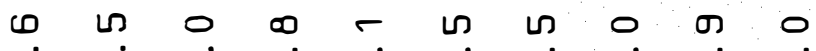

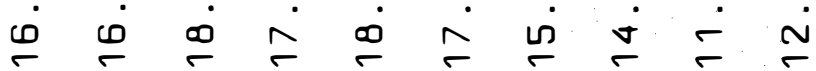

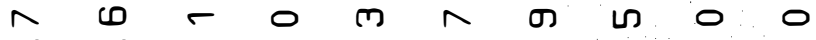

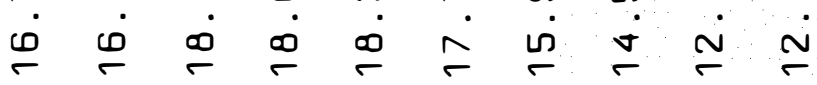

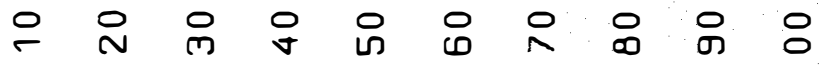

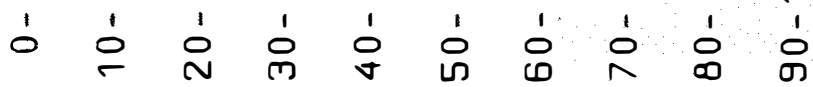




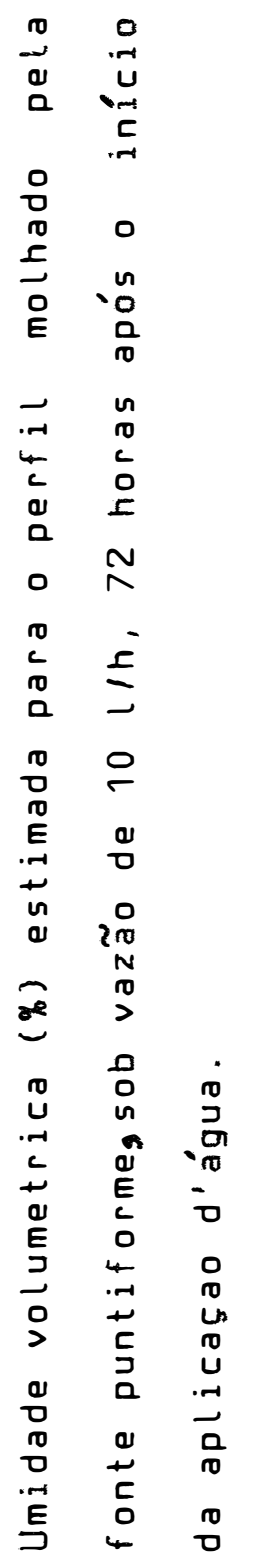

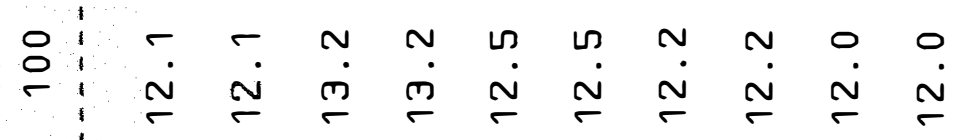

ด โ

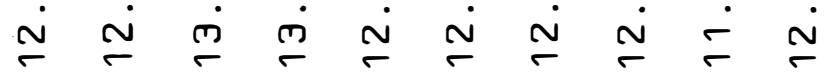

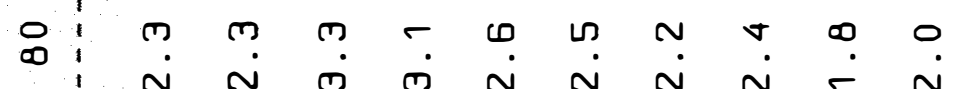

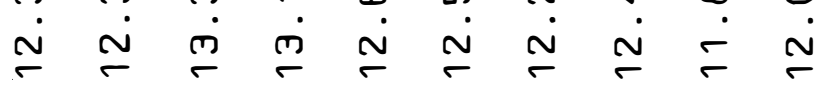

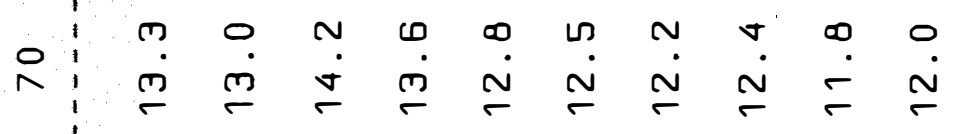

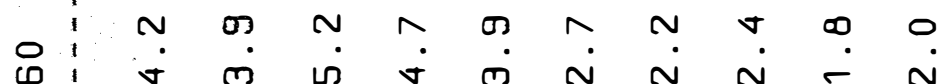

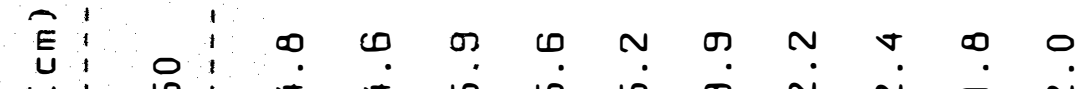
U ம: $\vec{r}:$

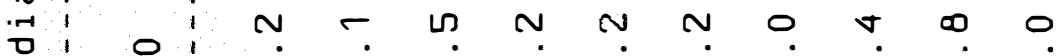
ரி ro

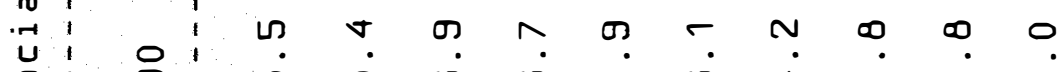

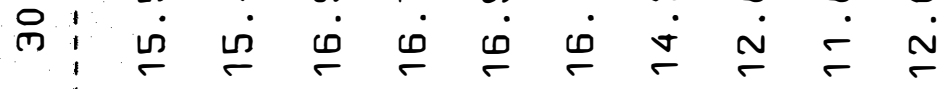
$+$ $\operatorname{lin}_{n \rightarrow 1}^{n}$

D:

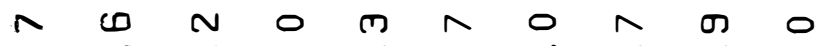

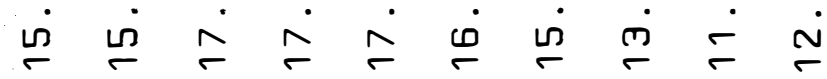

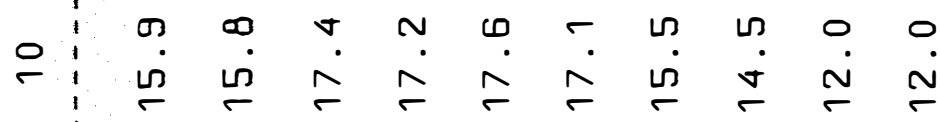

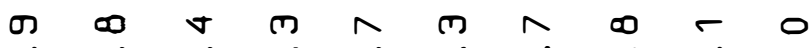
-

$M$

0
0
0
0
0

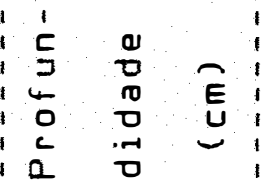

$\therefore$ 융 8 i

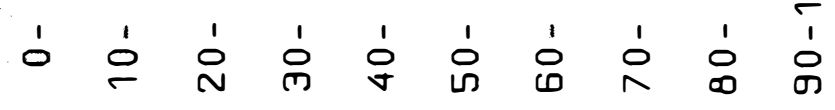


Tabela 14 - Umidade volumetrica média (\%) estimada para o perfil molhado pela fonte puntiforme, 24 horas apos o inicio da aplicaçơo d'água.

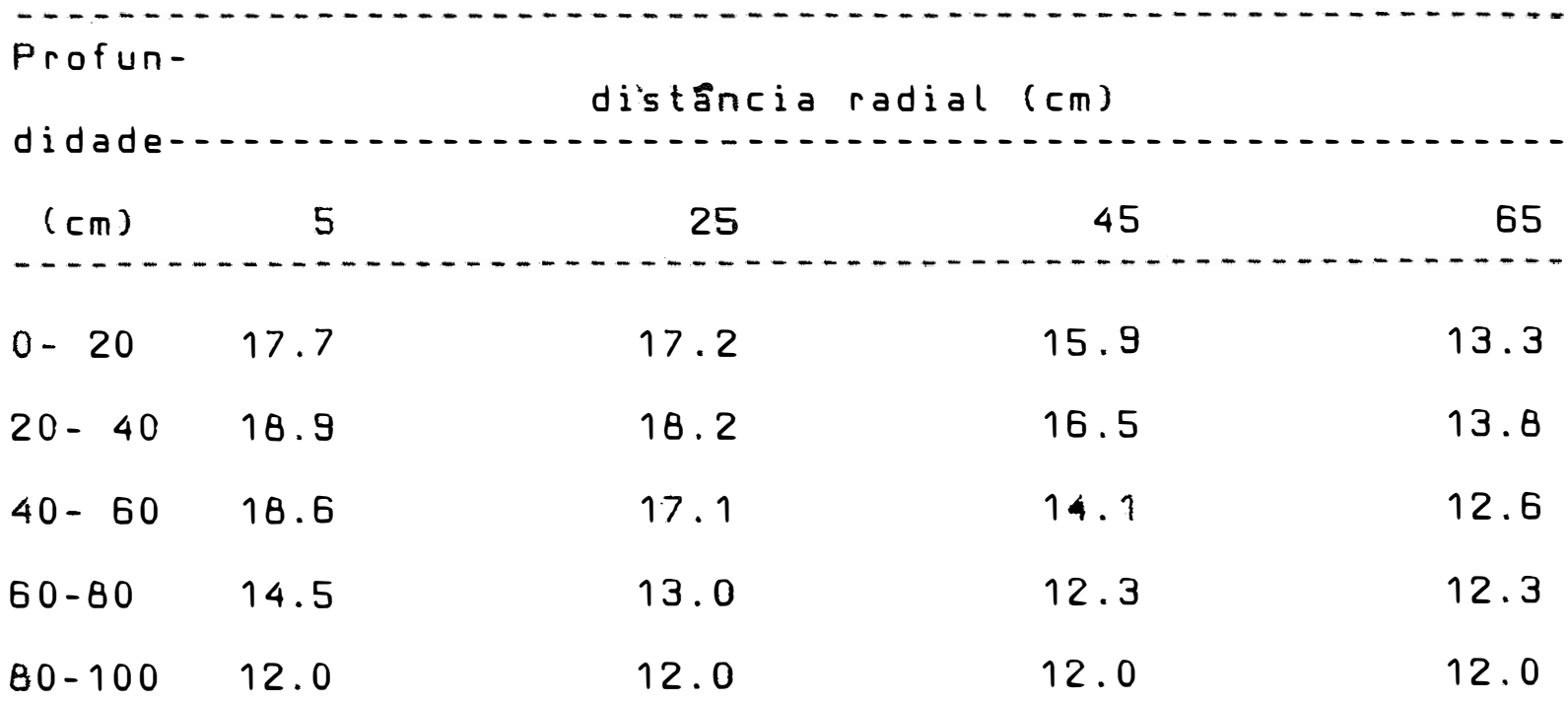


Tabela 15 - Umidade volumétrica média (\%) estimada para o perfil molhado pela fonte puntiforme, 48 horas após o início da aplicaço d'água.

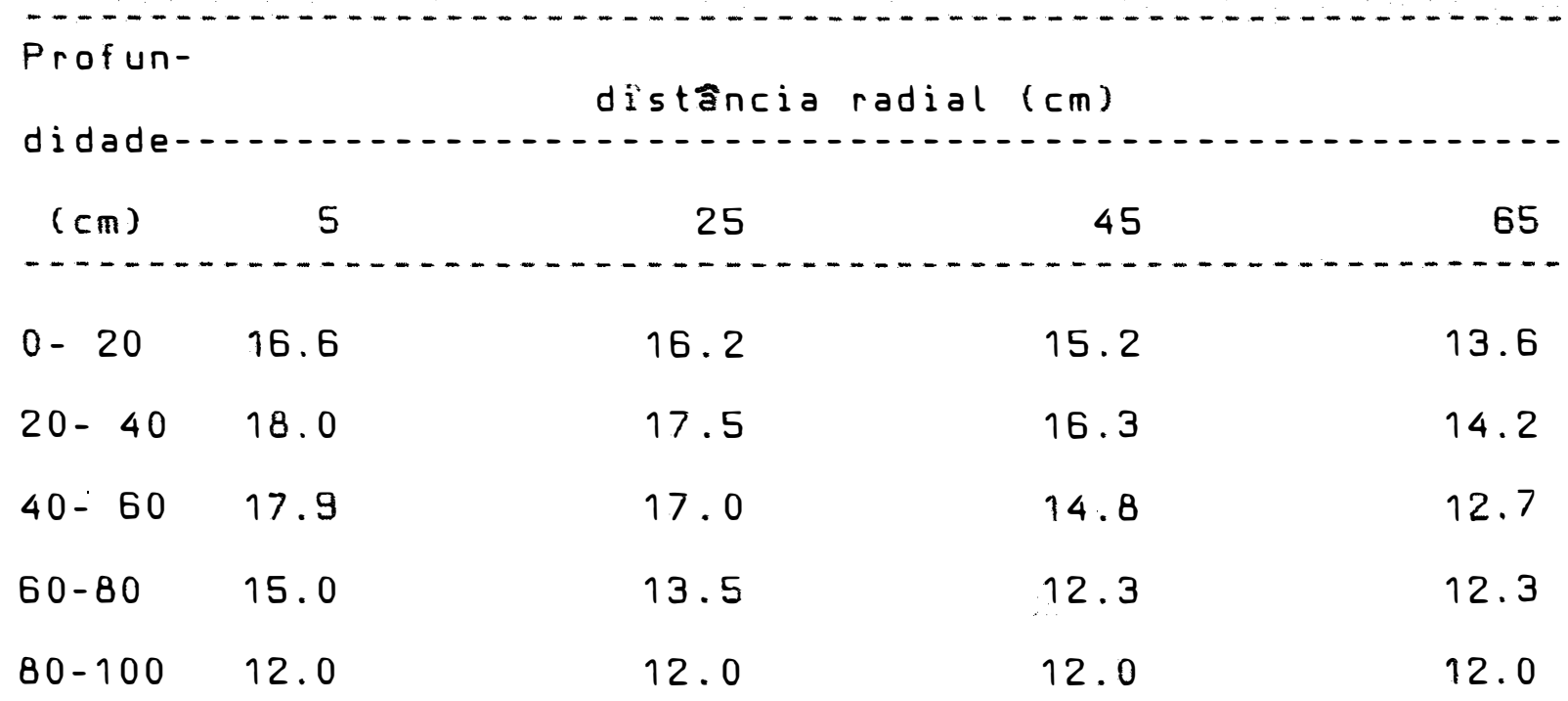


Tabela 16 - Umidade volumétrica média (\%) estimada para o perfil molhado pela fonte puntiforme, 72 horas apbs o inicio da aplicação d'ågua.

$\begin{array}{lcccc}\text { Profun } & & \\ (\mathrm{cm}) & 5 & 25 & 45 & 65 \\ 0-20 & 15.9 & 15.6 & 14.9 & 13.6 \\ 20-40 & 17.3 & 17.0 & 16.1 & 14.4 \\ 40-60 & 17.4 & 16.8 & 15.1 & 13.0 \\ 60-80 & 15.1 & 13.9 & 12.5 & 12.3 \\ 80-100 & 12.0 & 11.9 & 11.9 & 11.9\end{array}$




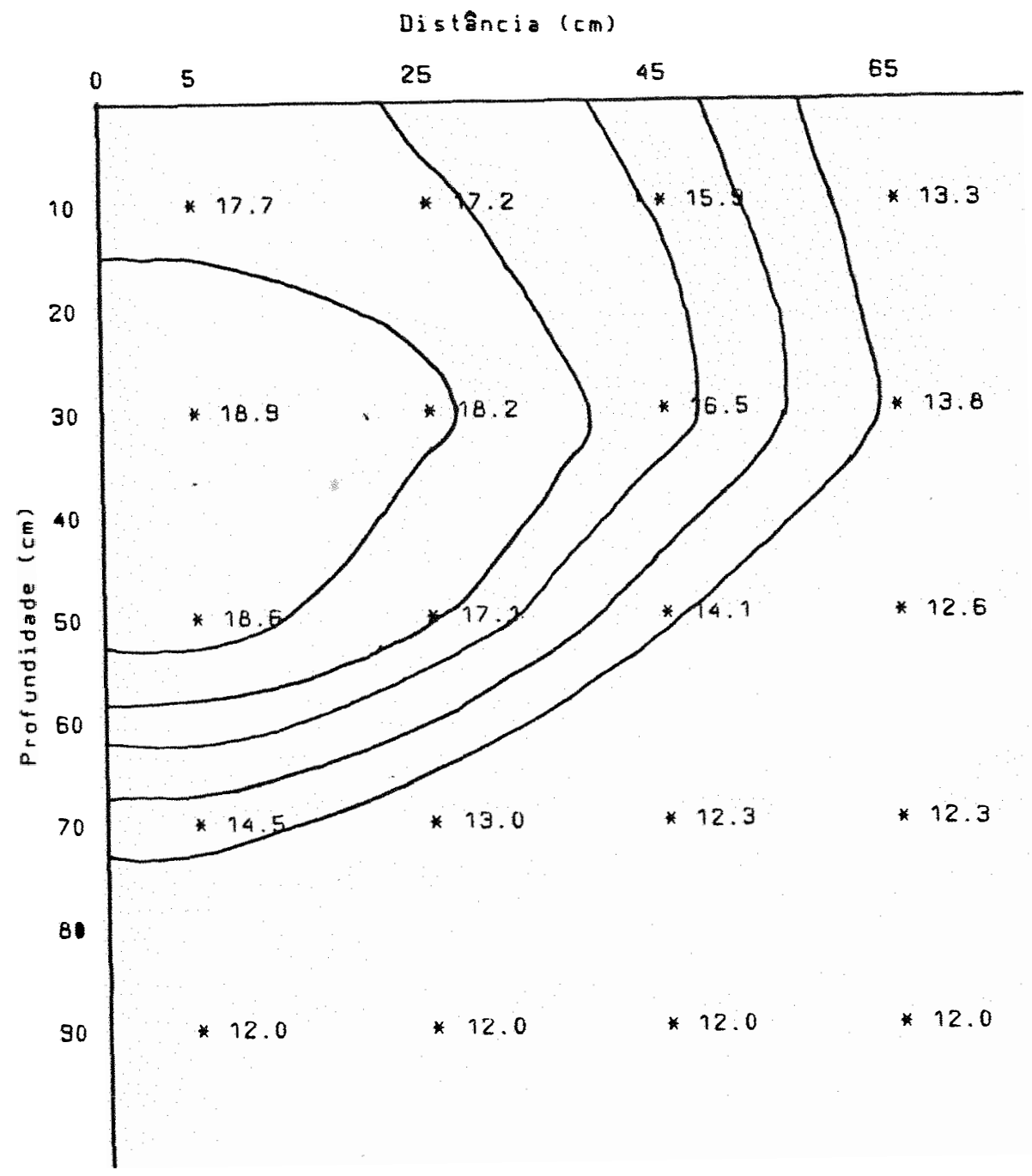

Figura 12 - Fertil de distribuiçăo de umidade, simulado para 24 horas, após o inicio da aplicaçăo de agua. 


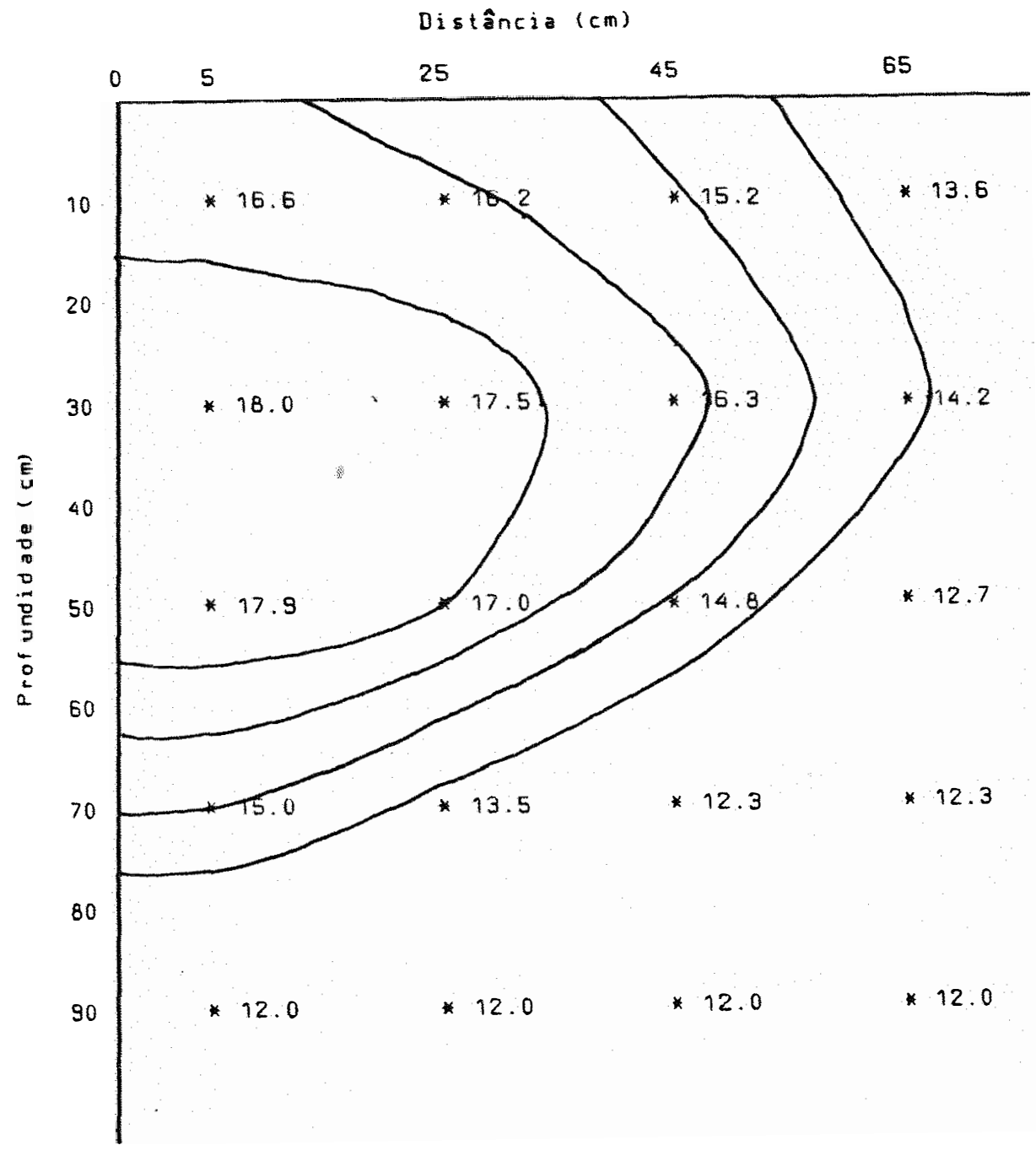

Figura 13 - Perfil de distribuiço de umidade, simulado para 48 horas, apos o inicio da aplicafao de água. 


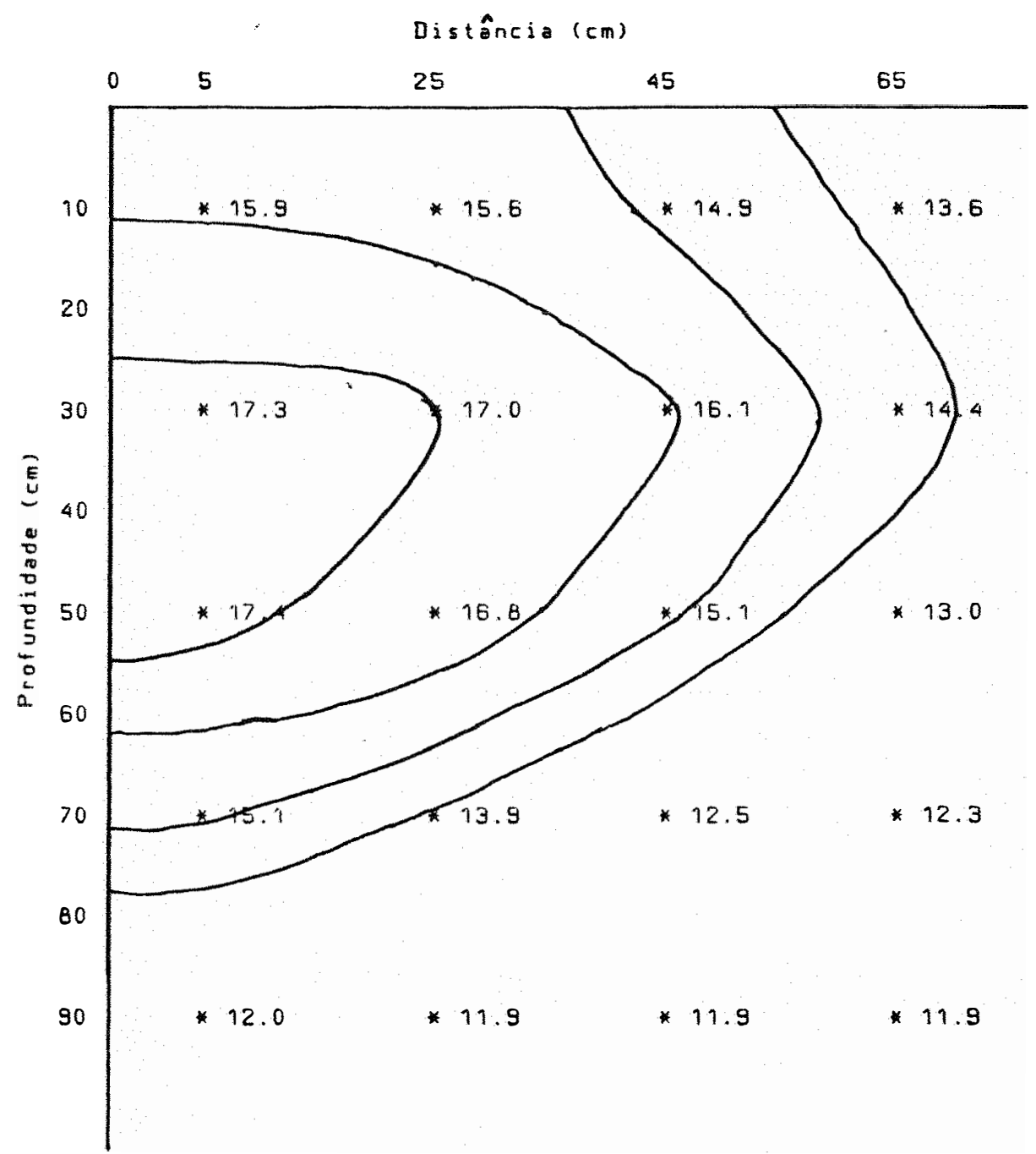

Figura 14 - Perfil de distribuiça de umidade, simulado para 72 horas, após o inicio da aplicacăo de água. 
Ds dados das Tabelas 8,9 e 10 foram comparados com os das Tabelas 14, 15 e 16, respectivamente, por meio de análise de regressăo, onde observou que a nivel de $1 \%$ de probabilidade, houve correlaçăo entre os dados observados e simulados para todos tres tempos estudados $(24,48$ e 72 horas, apds a aplicaçăo d’água). Os coeficientes de correlaçăo foram $0,91,0,92$ e 0,77 , respectivamente para os tempos de 24, 48 e 72 horas, após o inicio da aplicaçăo d'agua.

As diferenças ocorridas entre os dados simulados $e$ os obtidos a campo podem ser atribuidas aos seguintes fatores: variabilidade espaçial do solo, erros ou imprecisoies nas determinaç8es dos parametros do solo utilizados no modelo, erros provinientes de criterios teóricos, como a adoçăo da condutividade hidráulica entre dois anéis, a partir da media aritmetica da condutividade hidráulica de cada anel individual, e erros devido a histerese durante o processo de infiltraço.

Um fato observado tanto nos perfis simulados quanto nos obtidos a campo, foi que o máximo teor de água se situa na regiăo central do "bulbo" molhado a uma profundidade compreendida entre 30 a $40 \mathrm{~cm}$. 
5 - CONCLUSÕES

A análise dos resultados apresentados neste trabalho, mostrou a nivel de $1 \%$ de probabilidade, que houve correlaçăo entre os dados de distribuiça de água simulados pelo modelo matemático e observados a campo, o que permite afirmar que a distribuiça espacial da água em solo sob uma fonte puntiforme, pode ser estimada a partir dos dados da curva caracteristica do potencial de água no solo, da condutividade hidráulica saturada, da umidade inicial, da vazao do emissor e do volume de água aplicado, utilizando do modelo matemático para computador, proposto.

A regiăo com máximo teor de água se situou no centro do "bulbo" molhado, a uma profundidade compreendida entre 30 a $40 \mathrm{~cm}$. 
6 - LITERATURA CITADA

BRADT, A.; BRESLER, E.; DINER, N.; BEN-ASHER, I ; HELLER, J.; GOLDBERG, D. Infiltration from a trickle source: I. matematical models. Soil Sci. Soc. Amer. Prof, Madison, 35:675-682, 1971.

BRADT, A.; BRESLER, E.; DINER, N.; BEN-ASHER, I ; HELLER, J.; GOLDBERG, D. Infiltration from a trickle source: II. experimental data and theorical preictions. Soil Sci. Soc. Aner. Proc., Madison, 35:683-689, 1971.

CHANIM, B.S.; NIMAH, M.N.; KAMAND,F. A model to predict emitter spacing from basic soil data. In: INTERNATIONAL DRIP/TRICKLE CONGRESS, 3. Fresno, 1985. Anais. P. $712-717$

DELLA LIBERA, C. L. Efeito da vazåo de um gotejador no escoamento da água no solo. Catanduva, 1976. 82p. (Doutorado Faculdade de Filosofia, Ciencias e Letras de Catanduva). 
GARDNER, W.R. Some steady state solutions of the unsatured moisture flow equation with application to evaporation from a water table. Soil science. Baltimore, $85: 228-232,1958$

GARDNER, W. R. e MAYHUGH, M. S. Solutions and tests of the diffusion equation for the movimento of water in soil. Soil Sci. Soc. Amer. Proc, Madison, 22:197 - 201, 1958.

HILLEL, D. Solo e fauai Fenomenas e Princínios Flsicos. Forto Alegre, UFRGS, 1970. 231p

KELLER, J. e KARMELI, D. Trickle irrigation design for optimal soil weting. In: INTERNATIONAL DRIP IRRIGATION CONGRESS, 2. San Diego, 1974. Anais. p. 240-245.

KHATRI, K. C.; BRQUGHTON, R. S.; JUTRAS, P.J. Computer model for soil moisture distribuition from a drip sourse. In: INTERNATIONAL DRIP/TRICKLE CONGRESS, 3. Fresno, 1985. Anajs: p. 760.

LIBARDI, P. L. Condutividade hidráulica do solo em condiçles de campo. Piracicaba, 1978. 113p. (Doutorado 
Escola Superior de Agricultura "Luiz de Queiraz"/USP) MARTINEZ, M. A. Comparaço entro potenciais de água no solo, medidos no campo e simulados. Vicosa, 1981. 51p (M.S. - Universidade Federal de Vicosa)

MOSTAGHIMI, S.; MITCHELL, J. K.; LEMBKE, W. D.; Effect of discharge rate on distribution of moisture in heavy soil irrigated from a trickle sourse. In: ASAE. American Society " of Agricultural Engineers. Paper n 81-2081. St Joseph, 1981. 15p.

MUALEN, $Y$. A new model for predicting the hydraulic conductivity of unsatured porous media. Water Resources Besearch. Washington; 12(3):513-522, 1976.

NAKAYAMA, F. S.; BUCKS, D.A., Irickle irrigation for cron prodution - Design, operation and management. New York, 1986.

NIELSEN, D. R.; BIGGAR, J. M.; DAUIDSON, J.M. Experimental consideration of diffusion analysis in unsatured flow problems. Soil Science Society of America Journal. Madison, 26(2): $107-112,1962$.

PAULETTO, E. A. Determinaçăo da condutividade hidráulica de solos a partir da curva de retenço de água. 
Piracicaba, 1986. 133p. (Doutorado - Escola Superior de Agricultura "Luiz de Queiroz"/USP)

PALL, R.; MORROW, C. T.; FRITTON, D. D. JARRETT, A. R. Madeling moisture flow fron a trickle source in the presence of an apple tree. In: ASAE. American Society of Agricultural Engineers. Paper $n$ 81-2079. St Joseph, 1981. 35p.

PHILIP, J.P. Theory of infiltration. Ad. Hidrascience, 5: 215-296. 1969

PHILIP, J. R. General theorem on steady infiltration from surface sources. With application to point and line sources. Sojl Sci. Soc. Amer. Proc., Madison, 35: 867 $871,1971$.

RAATS, P. A. C. Movement of water and salt under hight frequency irrigation In: INTERNATIONAL DRIP IRRIGATION CONGRESS, 2. San Diego, 1974. Anais. P. 222-227.

RANZANI, G.; FREIRE, 0.; KINJO, T. carta de 5oles do municínio de Pifacicaba. C.E.S., E.S.A. "Luiz de Queiroz", Piracicaba, 1966. 
RICHARDS, L. A. Capillary conduction od liquids through porous medium. Ehisics, 1931. 1:318-333.

ROTH, R. L. Soil moisture distribuition and wetting pattern from a point source. In: INTERNATIONAL DRIP IRRIGATION CONGFESS, 2. San Diego, 1974. Anais: P. $\quad 246-252$.

SHANI, H. Selecting 'dripper discharge and location to control root distribution In: INTERNATIONAL DRIP/TRICKLE CONGRESS, 3. Fresno, 1985. Anais. P. $718-723$

VAN DER PLQEG, R.F.; BENECKE, P. Unsteady, unsaturated, n-dimensional moisture flow in soil: A computer simulation program. Soil Sci. Sor. Amer. Erac. Madison, $38: 881-885,1974$.

VAN GENUCHTEN, M.Th. A closed-form equation for predicting the hidraulic condutivity of unsatured soils. Soil Sci. Sof. Am. I. Madison, 44:892-898, 1980

WARRICK, A. W. Time-dependent linearized infiltration I. Foint sources. Soil Sci. Sof. Amer. Rroc.s Madison, 38: $18-21,1974$. 
WARRICK, A. W. Point and 1 ine infiltration calculation of the wetted soil surface. Soil Sci. Soc. Amer. Proc., Madison, 49:1581-1583, 1985.

WARRICK, A. W. E LOMEN, D. O. Time-dependent linearized infiltration III. Strip and disc sources. Soil Sci. Soc. Amer. Proc., Madison, 40:639-643, 1976. 